\title{
Advanced High-Temperature Flexible TPS for Inflatable Aerodynamic Decelerators
}

\author{
Joseph A. Del Corso ${ }^{1}$, F. McNeil Cheatwood ${ }^{2}$, Walter E. Bruce III ${ }^{3}$, Stephen J. Hughes ${ }^{4}$ \\ NASA Langley Research Center \\ Email: Joseph.A.DelCorso@nasa.gov,F.M.Cheatwood@nasa.gov,Walter.E.Bruce@nasa.gov, \\ Stephen.J.Hughes@nasa.gov \\ and \\ Anthony M. Calomino 5 \\ NASA Glenn Research Center \\ Email: Anthony.M.Calomino@nasa.gov
}

\begin{abstract}
Typical entry vehicle aeroshells are limited in size by the launch vehicle shroud. Inflatable aerodynamic decelerators allow larger aeroshell diameters for entry vehicles because they are not constrained to the launch vehicle shroud diameter. During launch, the hypersonic inflatable aerodynamic decelerator (HIAD) is packed in a stowed configuration. Prior to atmospheric entry, the HIAD is deployed to produce a drag device many times larger than the launch shroud diameter. The large surface area of the inflatable aeroshell provides deceleration of high-mass entry vehicles at relatively low ballistic coefficients. Even for these low ballistic coefficients there is still appreciable heating, requiring the HIAD to employ a thermal protection system (TPS). This TPS must be capable of surviving the heat pulse, and the rigors of fabrication handling, high density packing, deployment, and aerodynamic loading.

This paper provides a comprehensive overview of flexible TPS tests and results, conducted over the last three years. This paper also includes an overview of each test facility, the general approach for testing flexible TPS, the thermal analysis methodology and results, and a comparison with 8-foot High Temperature Tunnel, Laser-Hardened Materials Evaluation Laboratory, and Panel Test Facility test data. Results are presented for a baseline TPS layup that can withstand a $20 \mathrm{~W} / \mathrm{cm}^{2}$ heat flux, silicon carbide (SiC) based TPS layup, and polyimide insulator TPS layup. Recent work has focused on developing material layups expected to survive heat flux loads up to $50 \mathrm{~W} / \mathrm{cm}^{2}$ (which is adequate for many potential applications), future work will consider concepts capable of withstanding more than $100 \mathrm{~W} / \mathrm{cm}^{2}$ incident radiant heat flux. This paper provides an overview of the experimental setup, material layup configurations, facility conditions, and planned future flexible TPS activities.
\end{abstract}

\section{Nomenclature}

$1-D=1$-dimensional

3-D $=3$-dimensional

$8^{\prime} H T T=8$ Foot High Temperature Tunnel

${ }^{\circ} \mathrm{C}=$ centigrade

${ }^{1}$ HIAD Flexible TPS Lead, ED/Structural and Thermal Systems Branch, NASA LaRC/MS 431

${ }^{2}$ HIAD Principle Investigator, ED/Atmospheric Flight and Entry Systems Branch, NASA LaRC/MS 264

${ }^{3}$ HIAD Thermal Lead, ED/Structural and Thermal Systems Branch, NASA LaRC/MS 431

${ }^{4}$ HIAD Chief Engineer, ED/Mechanical Systems Branch, NASA LaRC/MS 432

${ }^{5}$ HIAD Flexible Systems Development Principle Investigator, RX/Materials Research Engineering, NASA GRC 


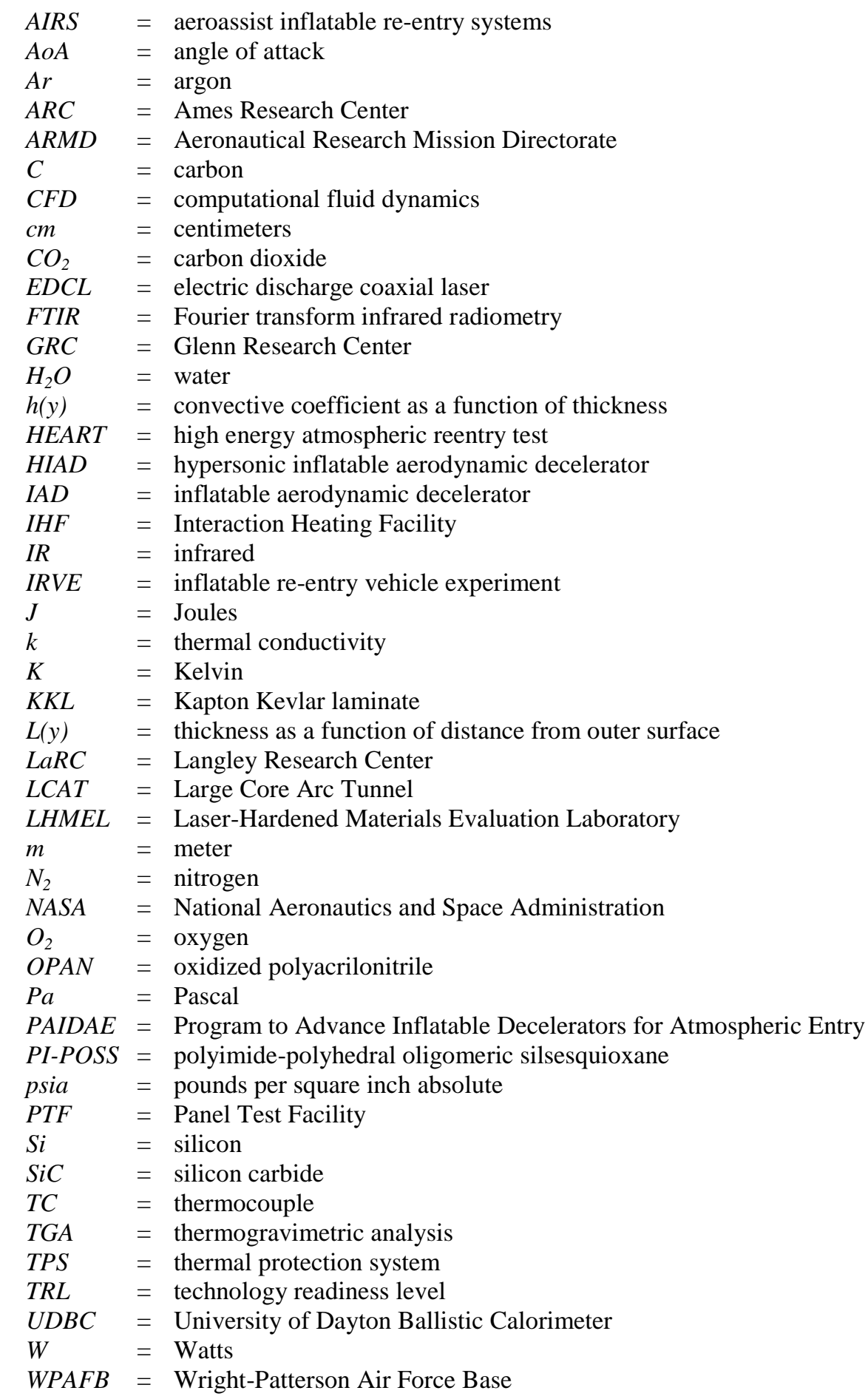

\section{I.Introduction}

The Aeronautical Research Mission Directorate (ARMD) Hypersonic Project at NASA has been developing advanced high-temperature flexible thermal protection system (TPS) for use with hypersonic inflatable aerodynamic decelerators (HIADs). The effort has involved research, ground testing, and analysis necessary to characterize performance of flexible TPS candidates prior to flight testing. To date, candidate material layups have been tested at the 8-Foot High Temperature Tunnel ${ }^{1}$ (8'HTT) at NASA Langley Research Center (LaRC), Laser Hardened Materials Evaluation Laboratory ${ }^{2}$ (LHMEL) at Wright-Patterson Air Force Base (WPAFB), and Panel 
Test Facility ${ }^{3}$ (PTF) at NASA Ames Research Center (ARC), at conditions representative of those calculated for potential HIAD applications. The first 8 'HTT test series ${ }^{4}$, conducted in December 2008, utilized readily available tunnel hardware and material combinations and resulted in expanding the understanding of potential use and limitations of multi-material layups. The second 8'HTT test series, conducted in June 2009, evaluated only those material layups that survived the first test series which have a high potential for future application. In both test series, material layups were subjected to Mach 6.5 flow for 90 seconds, producing heat fluxes ranging from $6 \mathrm{~W} / \mathrm{cm}^{2}$ to $20 \mathrm{~W} / \mathrm{cm}^{2}$. The third test series, conducted at LHMEL, focused on attempting to replicate 8'HTT conditions, to evaluate the repeatability of the material layup thermal response. The tests at LHMEL were also used to validate and exercise the robustness of the thermal model. In addition, samples were subjected to and survived conditions of more than $30 \mathrm{~W} / \mathrm{cm}^{2}$ heat flux for 90 seconds, and the silicon carbide (SiC) layup survived $94 \mathrm{~W} / \mathrm{cm}^{2}$ heat flux. The fourth test series, conducted at the PTF, utilized a semi-elliptic nozzle with an articulating sample fixture. The tests at PTF were focused on developing test techniques and verifying the results obtained at the 8'HTT and LHMEL tests.

The flexible TPS effort, which is part of ARMD Hypersonics Project, has been developing advanced hightemperature flexible TPS for use on HIADs. The flexible TPS effort has been tasked with increasing the technology readiness level (TRL) level of a first generation TPS that can withstand a heat flux of $20 \mathrm{~W} / \mathrm{cm}^{2}$ for flight, developing and characterizing second generation TPS materials and layups, and testing the thermal performance of TPS layups in flight-relevant environments. The first generation TPS able to withstand a heat flux of $20 \mathrm{~W} / \mathrm{cm}^{2}$ is henceforth called the baseline TPS. Flexible TPS testing performed during the Program to Advance Inflatable Decelerators for Atmospheric Entry (PAIDAE) test series ${ }^{5}$ contributed to developing and validating the first baseline layup for flight. This paper provides a general overview on materials and layups tested, facility testing and conditions, and thermal performance results. Specific results focus on three TPS layups, including the baseline flexible TPS for Inflatable Re-entry Vehicle Experiment-3 (IRVE-3), a TPS layup utilizing NASA Glenn Research Center (GRC) developed polyimide-polyhedral oligomeric silsesquioxane (PI-POSS) insulator, and a TPS layup with a $\mathrm{SiC}$ outer fabric. The baseline layup TPS that can withstand a heat flux of $20 \mathrm{~W} / \mathrm{cm}^{2}$ was evaluated at all three of the test facilities discussed in this paper, and was used to help validate a diffusion based thermal model. The PI-POSS layups were tested at LHMEL, and the results are presented which show survivability of the TPS layup at the $20 \mathrm{~W} / \mathrm{cm}^{2}$ heat flux condition. The $\mathrm{SiC}$ layup was specifically tested at $94 \mathrm{~W} / \mathrm{cm}^{2}$ heat flux for 90 seconds, and at $47 \mathrm{~W} / \mathrm{cm}^{2}$ heat flux for a period of 200 seconds.

\section{HIAD Flexible TPS Requirements}

The development of HIAD entry systems necessitates a discussion of requirements associated with flexible aeroshell. The aeroshell is comprised of structural and TPS components. The structure is constructed from a series of stacked inflatable torus tied to each other and to the vehicle with a network of straps. The straps maintain the desired shape of the aeroshell under aerodynamic load. The TPS is constructed from high temperature fabrics, insulators and a gas barrier. The TPS protects the inflated structure and vehicle from the aerothermal environment. The current design for the third IRVE-3 aeroshell, shown in Figure 1, is a 3 m diameter, $60^{\circ}$ half angle cone configuration with TPS on the fore body, or windward side, only.

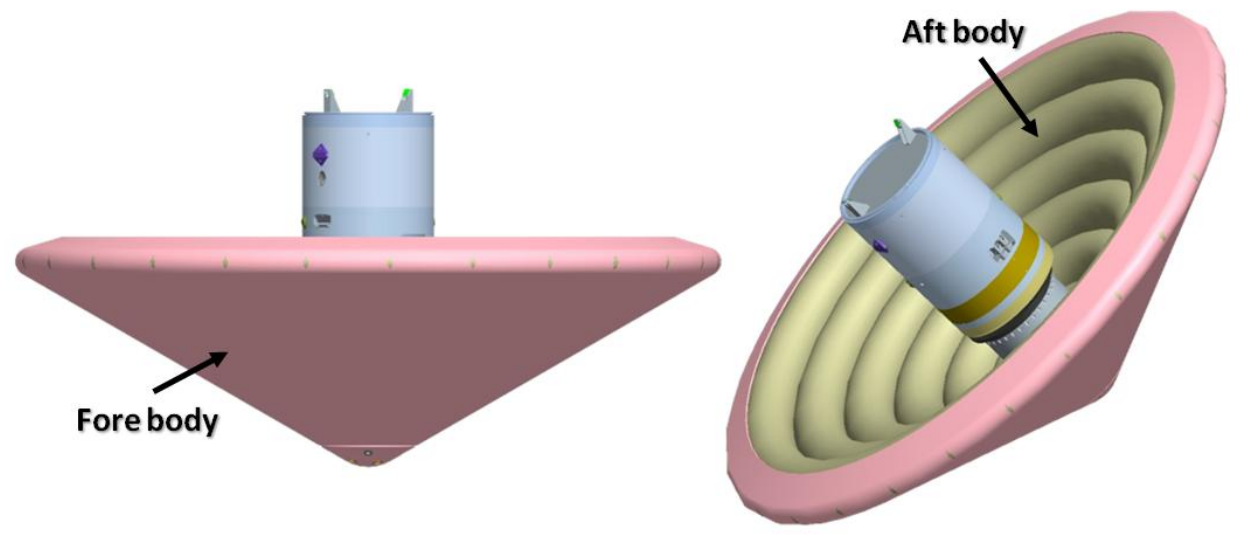

Figure 1. Schematic of IRVE-3 stacked torus side view (left) and three-quarter view (right).

The IRVE-3 flight aeroshell is required to withstand three hard packs without significantly damaging the aeroshell or negatively affecting the performance of the TPS during entry conditions. A hard pack is the packed and 
stowed state of the deflated aeroshell. The need for surviving three hard packs was derived from the ground operations leading up to flight, which includes an integrated systems test with deployment of the aeroshell from stowed configuration, followed by a single hard pack for flight. The third hard pack is required in the unlikely event that a second integrated systems test is necessary.

The TPS for the aeroshell must be rugged enough to withstand the packing process, including handling of the material, packing to high densities of $400 \mathrm{~kg} / \mathrm{m}^{3}$, and hard creases (near zero bend radii), as well as deployment after long duration exposure to mission relevant environments without significantly changing the thermal physical characteristics of the TPS. Ultimately, the flexible TPS must be tested to demonstrate performance with positive margins at entry aerothermal and mechanical environments. The behaviour of flexible TPS subjected to a range of heat fluxes also must be understood to be able to model and reliably determine the performance of the TPS.

\section{Mission Profiles}

The IRVE-II flight, and nominal flight trajectories for upcoming HIAD missions, IRVE-3, IRVE-4, and High Energy Atmospheric Re-entry Test (HEART), is presented in Figure 2 as a function of altitude and velocity. In addition, the IRVE-II trajectory ${ }^{6}$ is included for reference. The point of maximum heating and maximum stagnation pressure are indicated along the trajectory with the maximum heating occurring at a higher altitude and velocity than the maximum pressure for each case. The maximum heating occurring at higher altitude and velocity than the maximum pressures for each case results in the pressure profile and the heat flux profile, for each trajectory, being slightly offset, so that the maximum pressure and maximum heat flux do not occur at the same time.

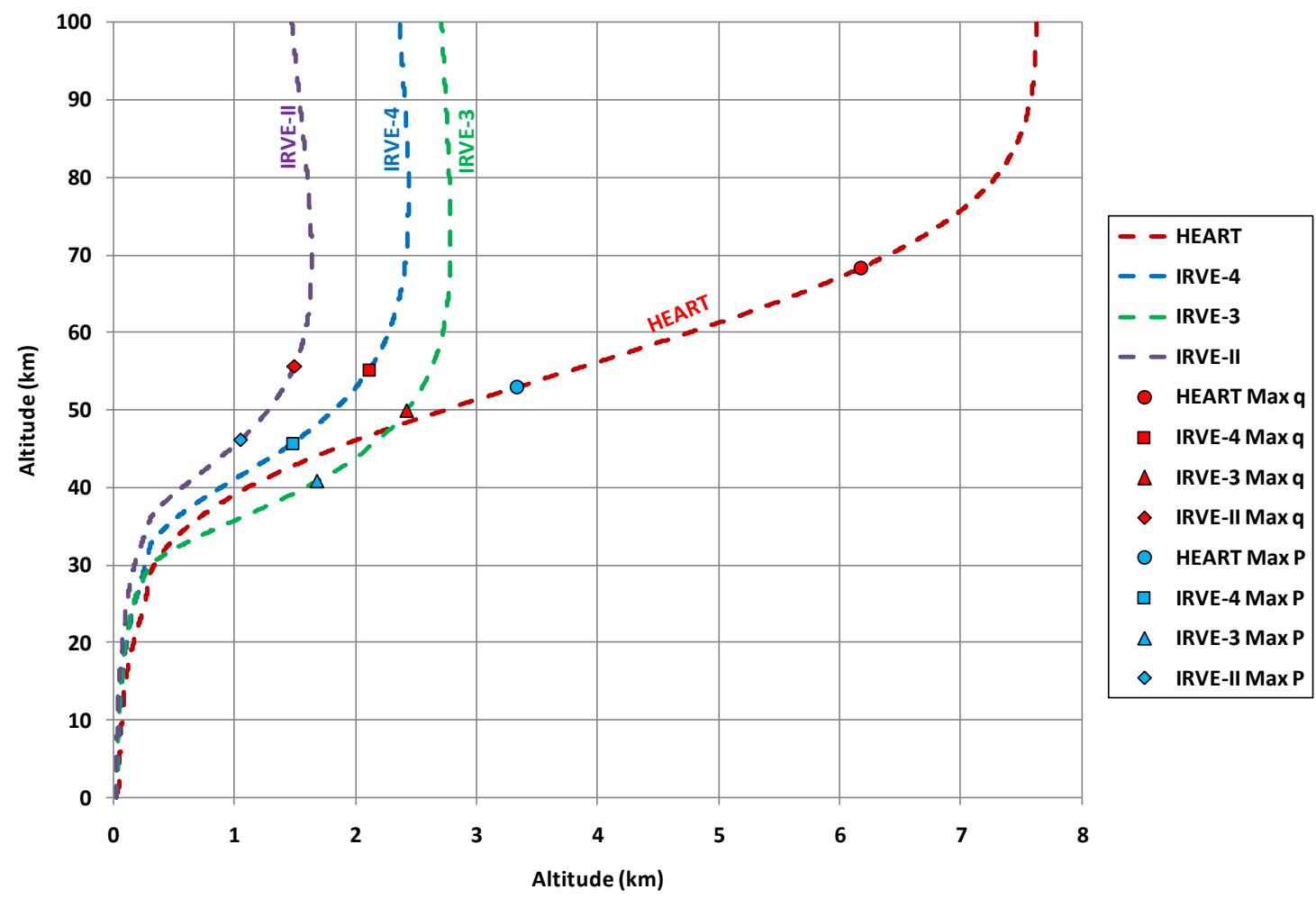

Figure 2. HIAD mission trajectories - altitude vs. velocity.

The offset in the pressure and heating profiles presents difficulties for the ground based testing effort as testing is not feasible to the exact mission profile or perform numerous tests at various sets of conditions. Therefore, for the HIAD development and testing effort, a methodology of testing at the maximum heat flux and pressure simultaneously is adopted. This concept is shown in Figure 3 where each of the HIAD trajectories is plotted as a function of heat flux and surface pressure. Using the highest heat flux and pressure values results in the desired test points for each mission. In addition to matching the heat flux and pressure, the surface shear force on the TPS and the flow-field enthalpy are also matched for the best simulation of flight. 
The HIAD Program is evaluating various high-temperature test facilities for performing shear type testing to simulate flight-like conditions. In Figure 4, the facility pressure-heat flux performance envelopes is presented for some of the high-temperature, shear-type facilities ${ }^{7}$ that have been used for testing or are under consideration. Each of these facilities is discussed in detail in the next section.

The desired mission test points, along with the facility performance envelopes are presented in Figure 5. The data in Figure 5 indicates that no facility will match all of the desired test conditions. The PTF and Interaction Heating Facility ${ }^{3}$ (IHF) are sufficient for heat flux, but have a low pressure at all of the desired test points. Whereas, the 8'HTT is a good match for IRVE-4, but will exert a slightly higher pressure than required for IRVE-3. The 8 'HTT cannot simulate the higher energy returns that HEART will required.

The Boeing Large Core Arc Tunnel ${ }^{7}$ (LCAT) facility appears to be the single best facility, in terms of matching the pressure and heat flux, for the upcoming HIAD missions under consideration and is the only facility that can directly match the desired HEART test condition. In addition, the LCAT facility is the only facility that can produce a $50 \mathrm{~W} / \mathrm{cm}^{2}$ heat rate at a range of surface pressures as shown in Figure 4 . However, the facility performance profile for the LCAT facility is only an estimation, since the semi-elliptic nozzle that will be required to achieve the projected performance has not been calibrated, whereas test data is available for the other facilities. The HIAD Program has a calibration test effort for LCAT scheduled for the summer of 2011. Another drawback to the LCAT facility is that the facility has the smallest flow-field of the facilities presented. The small flow-field will result in rectangular test sample sizes no larger than about $10 \mathrm{~cm}$ by $15 \mathrm{~cm}$ where the 8 'HTT can test sample sizes up to about $60 \mathrm{~cm}$ by $60 \mathrm{~cm}$.

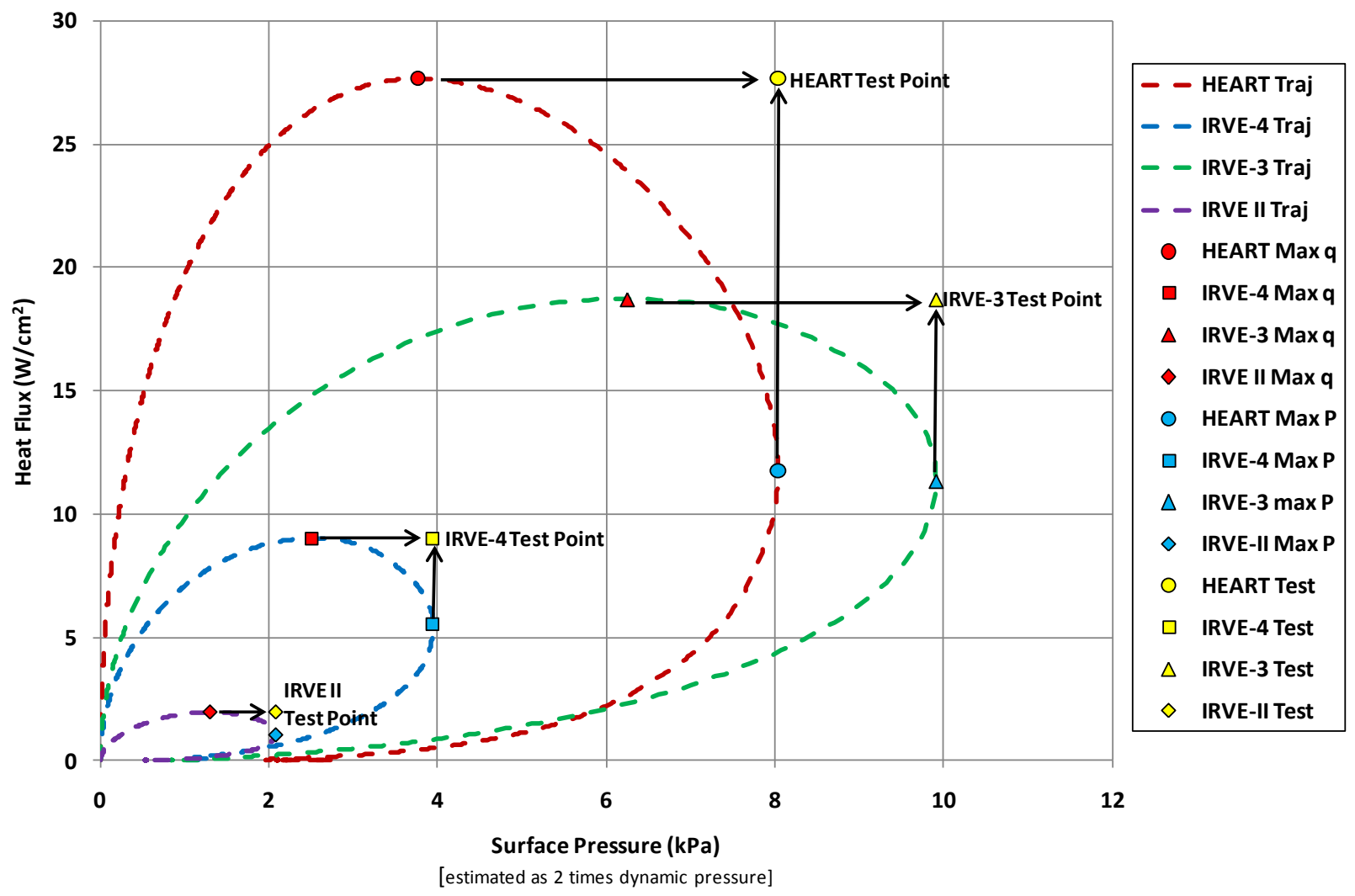

Figure 3. HIAD mission trajectories - heat flux vs. surface pressure. 


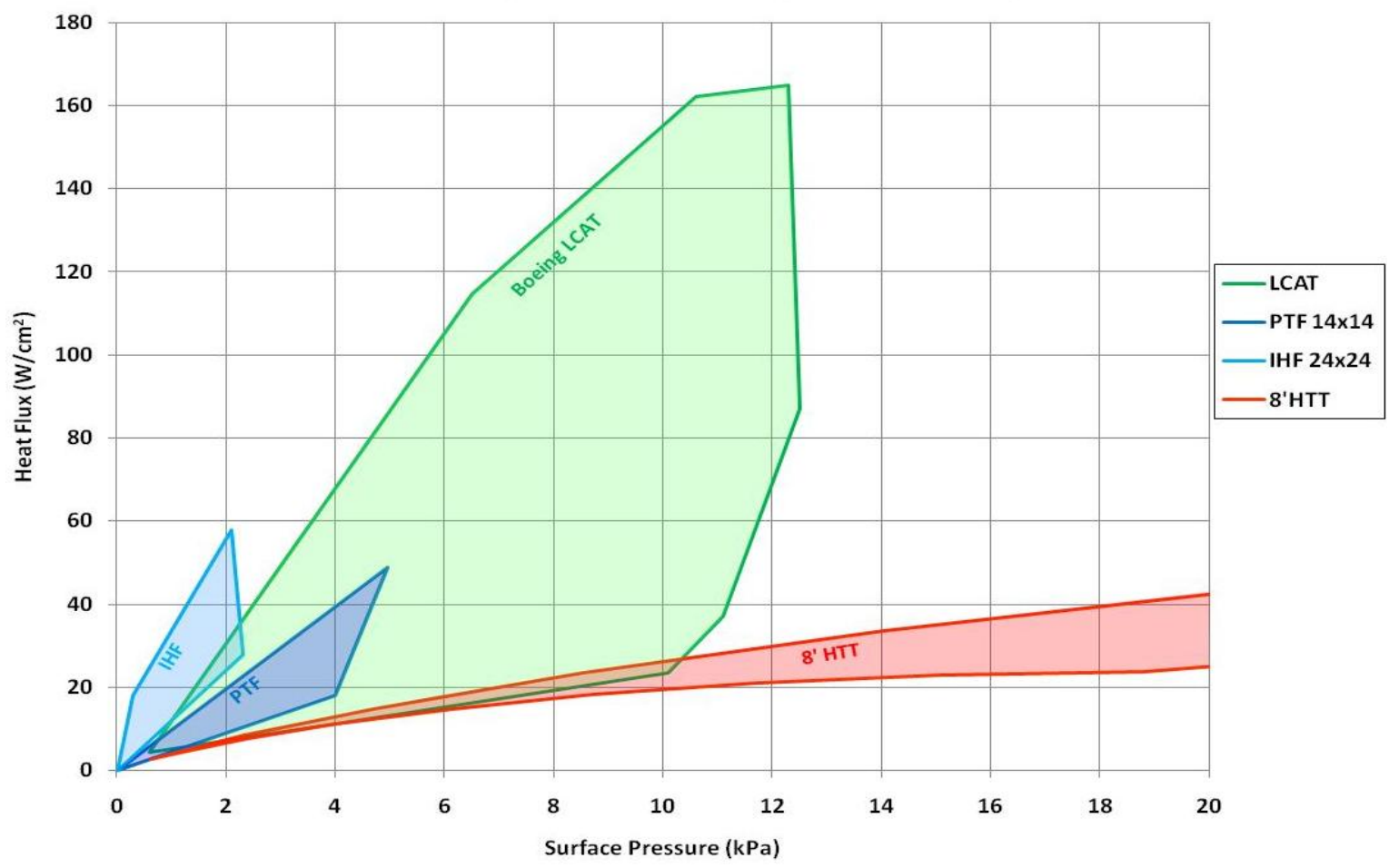

Figure 4. Facility performance envelopes for shear type testing.

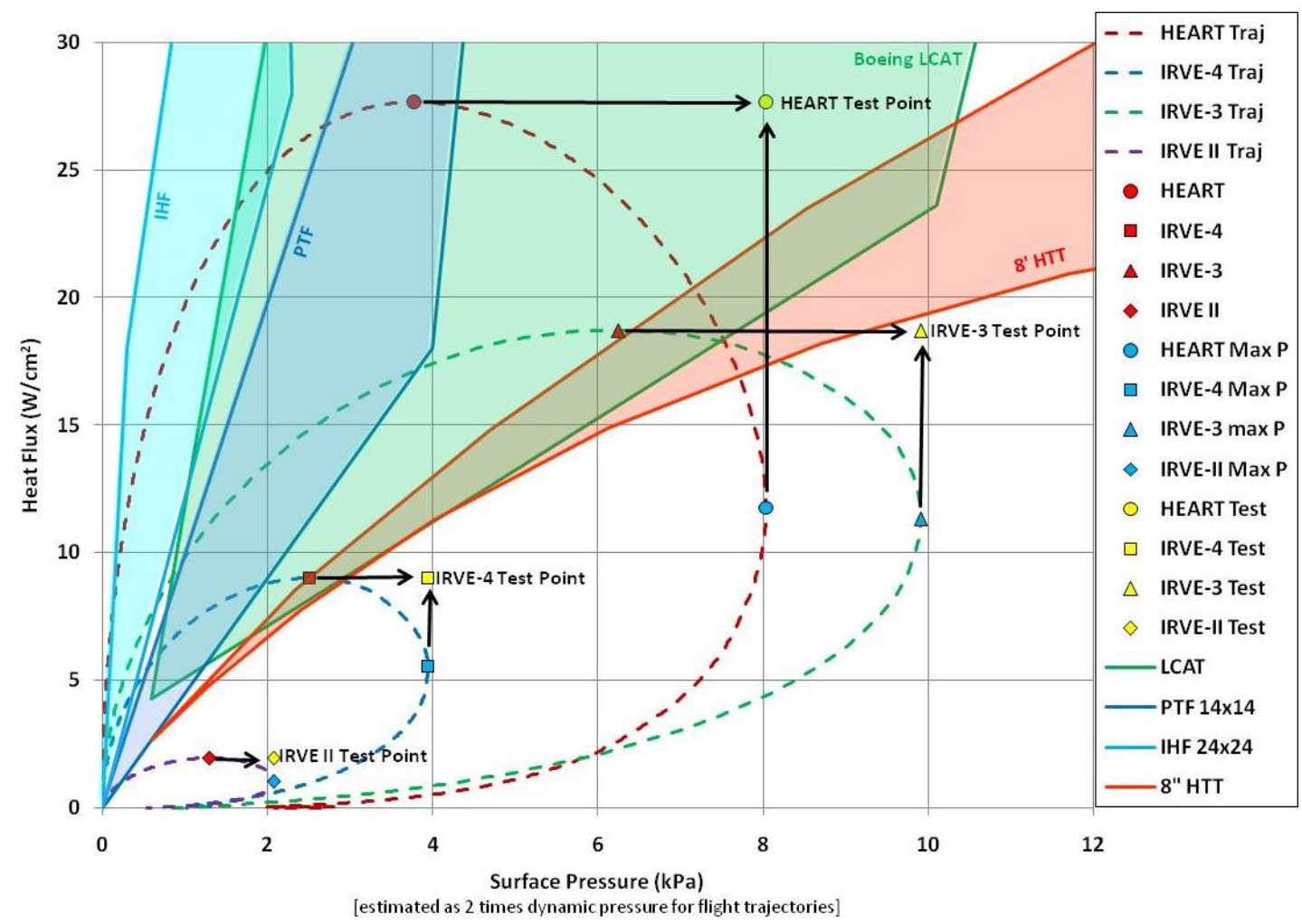

Figure 5. Facility performance envelopes and mission test points. 


\section{Test Facilities}

Beginning in 2007, candidate TPS layups were tested in the 8'HTT, PTF, and LHMEL. Test techniques for evaluating layup performance were developed at all three facilities. Each facility has its own unique aerodynamic envelopes which enabled testing to specific mission environments. The 8'HTT is a Mach 7 test facility, which was used in the first two PAIDAE test series to evaluate a broad range of layups made of commercial materials. Results from these first tests, conducted in the previous three years, allowed for appropriate down-selection of materials to carry forward as viable candidates in Flexible TPS testing. 8'HTT test conditions were relevant for IRVE (sounding rocket), and earth entry mission profiles. PTF, which was higher enthalpy flow at lower static pressure than PAIDAE testing, enabled evaluation of candidate layups at mission profile conditions relevant to Mars entry systems. LHMEL tests were conducted in a vacuum chamber, which enabled decoupling of shear and pressure effects.

The 8'HTT, shown in Figure 6, is a combustion-heated hypersonic blow down-to-atmosphere wind tunnel that provides flight simulation over a Mach number range from Mach 4 to Mach 7 and an altitude range from 15,000 $\mathrm{m}$ to $37,000 \mathrm{~m}^{8}$. The free-jet test section is in an $8 \mathrm{~m}$ diameter vacuum chamber and is able to accommodate the coupon sample holder test sled. The test sled is supported by a sting arm, and injected into the flow using an elevator mechanism. The test sample layups are flush-mounted to spaces built into the sled surfaces and are shown in Figure 7. The sled surface is instrumented with flush-mounted Schmidt-Boelter heat flux gages to the front and aft of the test coupons. The sled has two sample locations, one "flat" and one drafted up at $5^{\circ}$, allowing for two test conditions (heat rates and pressures) during a single tunnel run. ${ }^{9}$ Three video cameras capture each test run, and are mounted to provide coverage of the fore and aft sled test coupons, as well as a three-quarter view of the sled. Test runs are recorded on video, and pre- and post-test pictures are taken of the test coupons in the test fixture as well as photo-documentation of the decompiled layups.

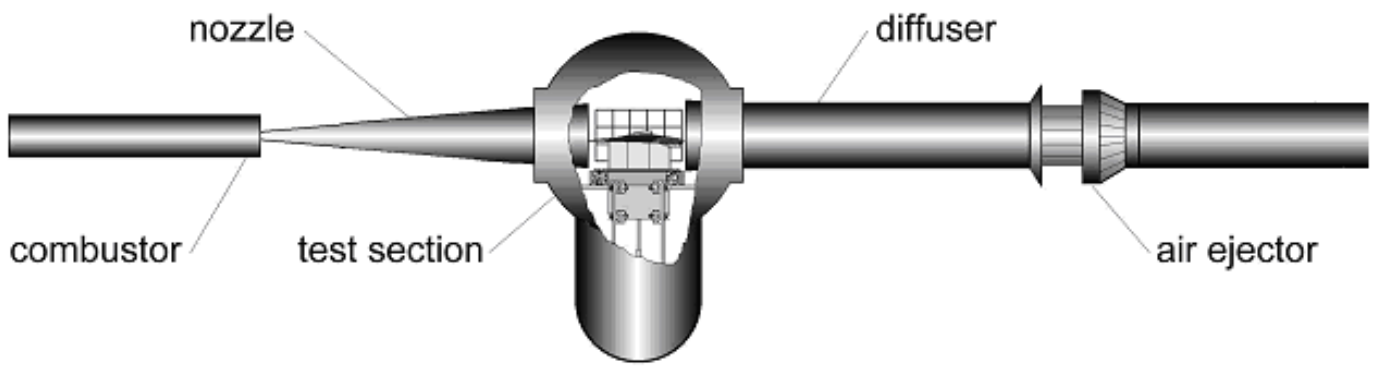

Figure 6. Schematic of the 8'HTT.

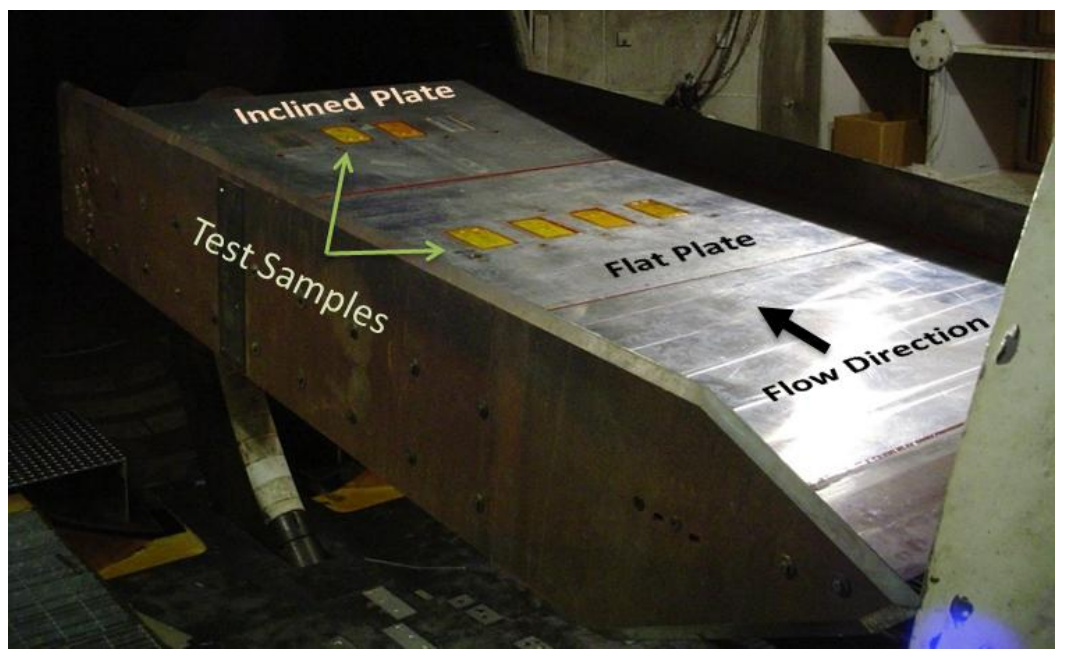

Figure 7. Picture of the 8'HTT sled with mounted samples (samples are orange).

The PTF, shown in Figure 8, consisted of a 20-MW segmented arc heater coupled to a semielliptical nozzle. The nozzle discharged in a semi-free jet within a $1.2 \mathrm{~m}$ by $1.2 \mathrm{~m}$ by $1.2 \mathrm{~m}$ test cabin where the panel test fixture 
attached at the nozzle exit. The test sample layups were installed in a $0.3 \mathrm{~m}$ by $0.3 \mathrm{~m}$ flat-panel fixture shown in Figure 9. The panel was able to be inclined at angles of $-4^{\circ}$ up to $15^{\circ}$, though $6^{\circ}$ was the practical maximum. The surface conditions on the flat-plate test articles were calibrated by changing the pitch angle of the panel plate relative to exit flow nozzle, and varying the arc operating parameters (current and mass flow rate). Flow was evacuated from the test chamber by a steam-ejector vacuum system, providing static pressures in the range of $1 \mathrm{kPa}$ to 100 $\mathrm{kPa}$. Optical access through side doors and the roof of the test cabin allowed for imaging of the flow and test articles. The test sample holder surface was instrumented with flush mounted Schmidt-Boelter heat flux gages and pressure transducers to the front and aft of the coupons to measure surface heating and surface pressure on the samples. Surface temperatures were measured with an optical pyrometer and calibrated against surface emittance values. Pyrometers were used to reference a temperature on infrared (IR) video captured during each run. Test runs were recorded on video, and pre- and post-test pictures were taken of the test coupons in the test fixture as well as photo-documentation of the decompiled layups.

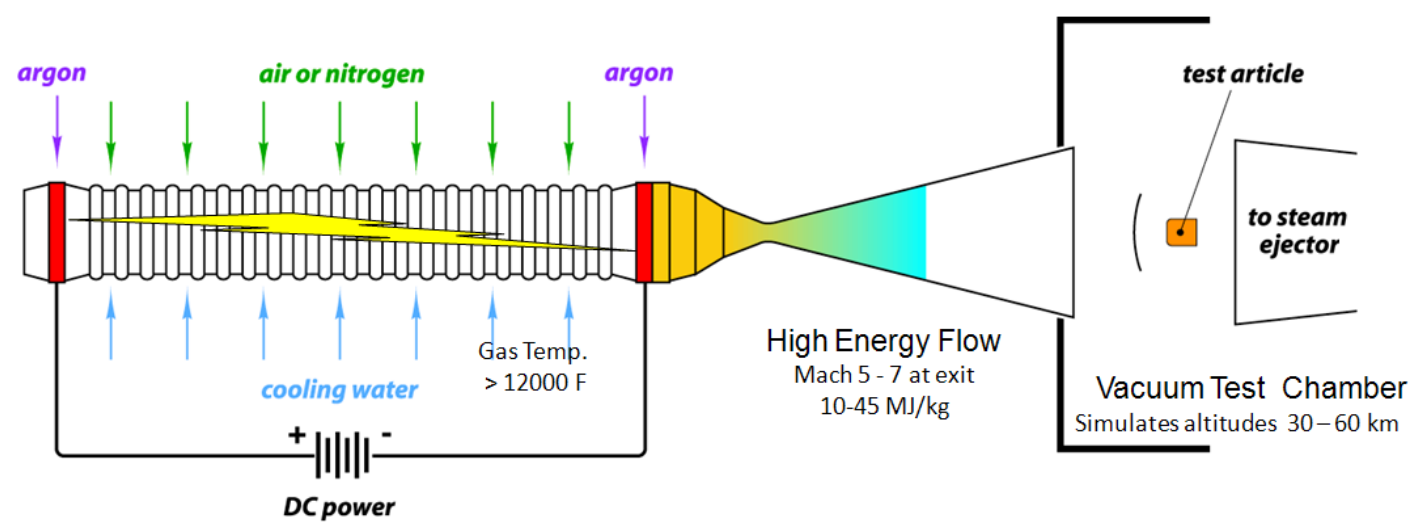

Figure 8. Schematic of the PTF.

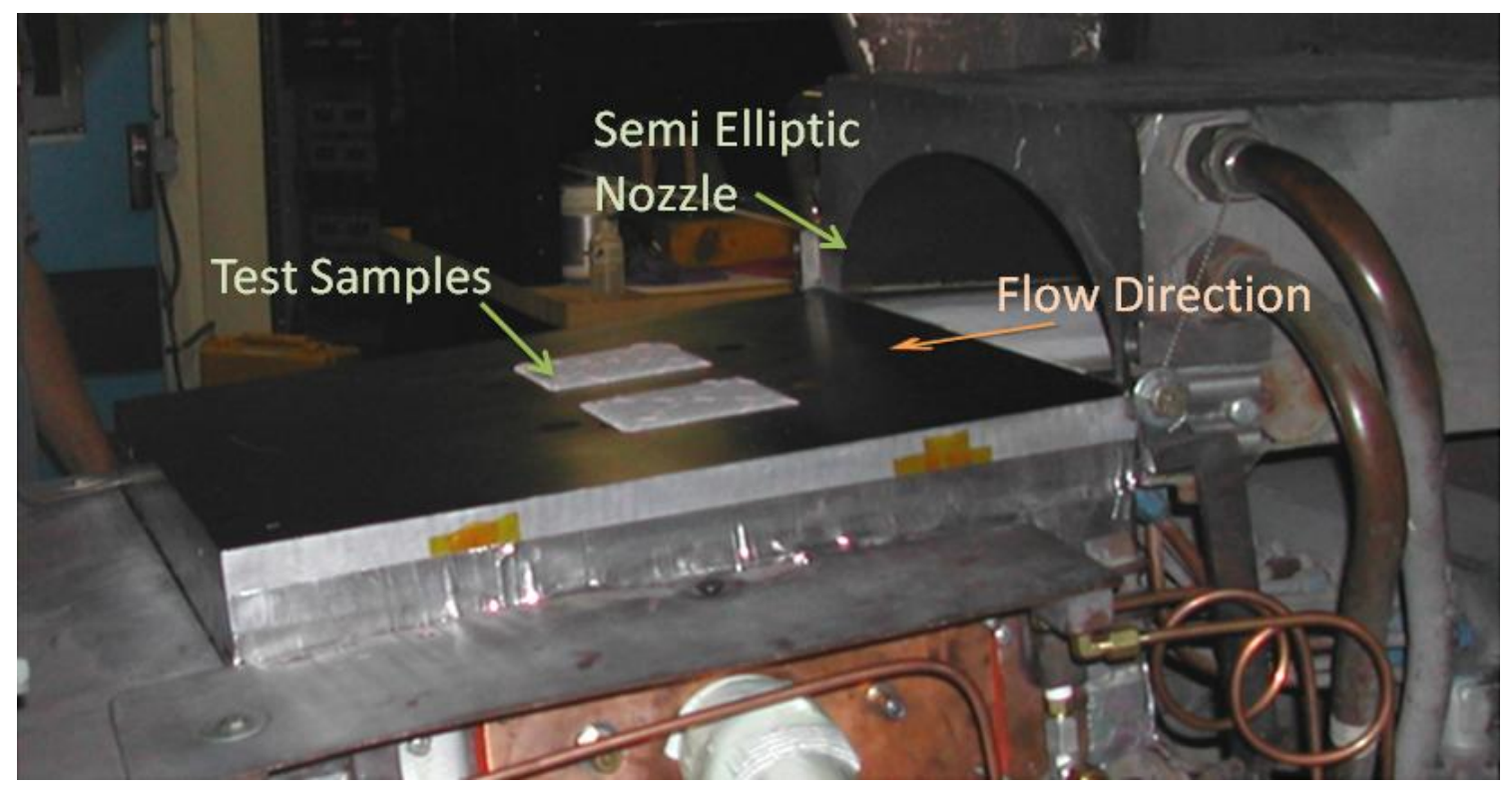

Figure 9. Picture of the PTF semielliptic nozzle and flush mounted test samples prior to a test run.

The LHMEL-I test facility shown in Figure 10 is a $15-\mathrm{kW}$ continuous wave carbon-dioxide $\left(\mathrm{CO}_{2}\right)$ electric discharge coaxial laser (EDCL). The laser operates at a wavelength of $10.6 \mu \mathrm{m}$, with a beam divergence at full angle of 8.9 milliradians. The test samples are installed in a sample holder frame within the $76 \mathrm{~cm}$ vacuum chamber, shown in Figure 11, able to achieve pressure of $1 \times 10^{-5}$ torr, and configured for laser testing. The applied 
heat flux is measured using a total capture University of Dayton Ballistic Calorimeter (UDBC), for calibration. During test runs, $1 \%$ of the main beam is captured by an integration sphere with a wavelength-insensitive thermopile detector with time constant on the order of tens of milliseconds. Surface temperatures are measured using a multicolor pyrometer. Corrections resulting from vacuum chamber windows are taken into account for laser losses, and pyrometer measurements.

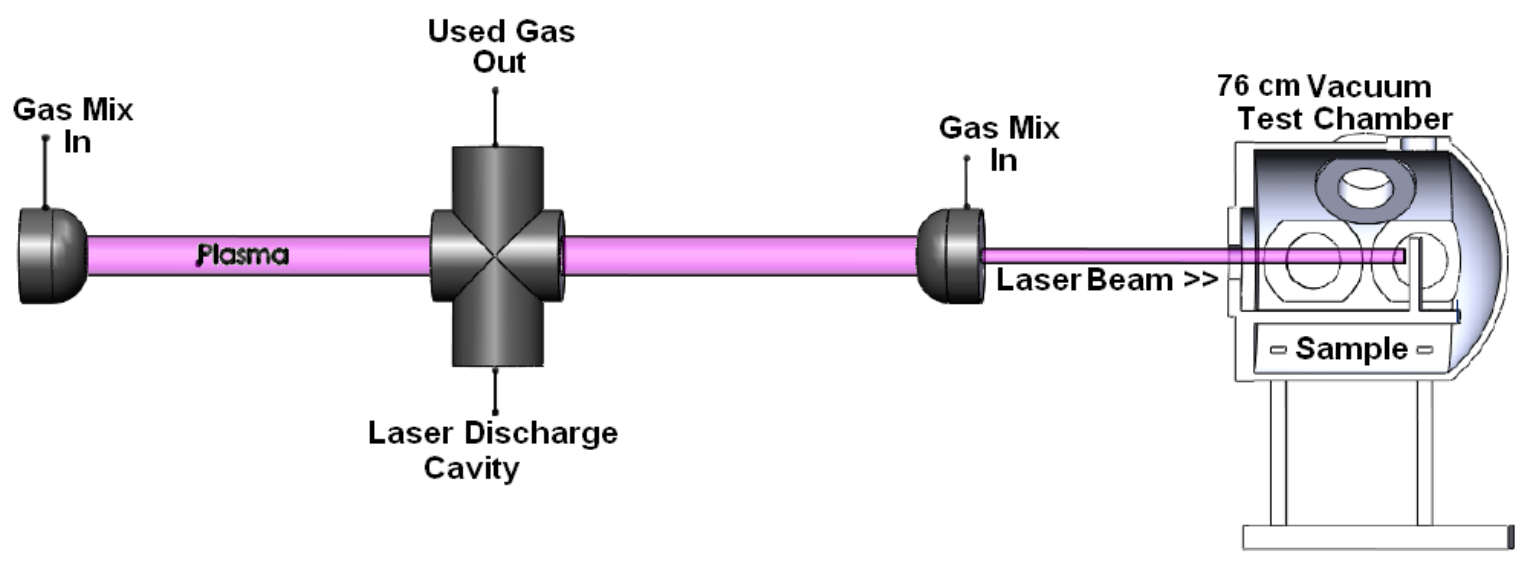

Figure 10. Schematic of the LHMEL-I Test Facility.

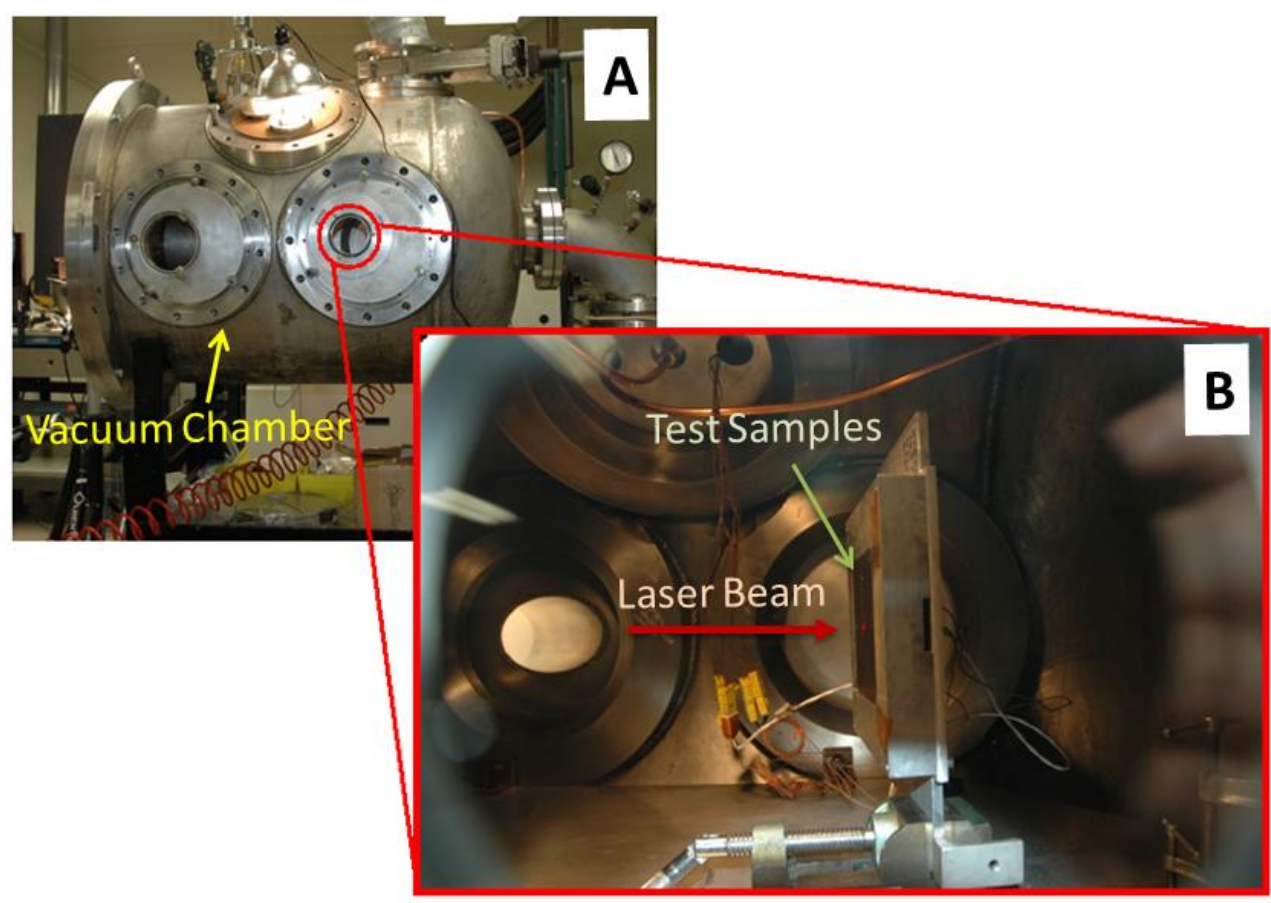

Figure 11. Pictures of the LHMEL $76 \mathrm{~cm}$ vacuum chamber (A) and test sample viewed through the vacuum chamber side window $(B)$.

\section{Flexible TPS Overview}

Flexible TPS is a TPS designed to maintain structural component temperatures while surviving the thermal loads, mechanical shear and pressure environments during re-entry. TPS layups are made up of multiple layers of materials and fabrics which satisfy specific engineering functional aspects. The baseline TPS, shown in Figure 12, has two layers of Nextel BF-20 outer fabrics which are exposed directly to entry aerodynamic environments and are intended to reduce or eliminate hot gas impingement and aerodynamic shear on the underlying plies. The two Pyrogel 3350 insulator layers manage the integrated heat load and are sized to maintain the TPS backside 
temperatures at, or below, maximum usable temperatures for the inflatable structure. The Kapton Kevlar laminate (KKL) gas barrier layer serves as both a TPS and a structural component. The Kapton is impermeable and serves to stop the flow path through the TPS, reducing or eliminating the potential for hot gas inflow through the TPS laminate, while the Kevlar provides a mechanical interface for attaching the TPS assembly to the inflatable structure as well as a mechanical ply to quilt the TPS assembly together.

Original material selections and layup configurations focused on several important features and characteristics. An optimized TPS would include materials with low areal weight and permeability, while still being malleable. Material selections for layups took into account high continuous use temperatures, insulators with low thermal transport, and outer fabrics with high emissivity and low catalicity. The materials should also be able to sustain performance after handling, rebound to original shape after compression, and maintain uniformity and homogeneity even after packing. Materials which particulate excessively when handled were considered, and some tested, but ultimately rejected because after handling, particulates would redistribute through the material resulting in non-uniform material performance. Additional considerations for off the shelf materials included maturity of manufacturing processes and the ability to produce a consistent product.

Insulators fall into three catagories: fully insulative, transpiration-insulative, and ablative. Fully insulative materials manage integrated heat loads by conduction and

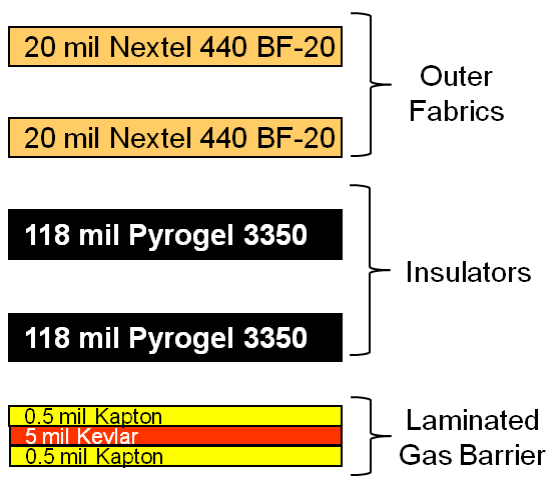

Figure 12. Baseline TPS functional aspects. radiation, and are limited to short duration heat pulses, or the ability to manage an interface temperature based on the thickness of the insulator and how long a heat pulse will conduct heat through the insulator (less than 200 seconds, $20 \mathrm{~W} / \mathrm{cm}^{2}$ to $50 \mathrm{~W} / \mathrm{cm}^{2}$ ). Transpiration-insulative materials manage heat by conduction, radiation, and endothermic processes with active out-gassing. Unlike ablators, transpiring insulators will outgas and char to a limited extent, but will not experience recession of the base material. Transpiring-insulators are generally lower temperature capable materials, and are intended to off-gas as a heat management mechanism. The transpiring-insulators can be tailored to a range of entry heat pulses and durations, but will tend to be used on intermediate duration and heat flux range trajectories (less than 500 seconds, $30 \mathrm{~W} / \mathrm{cm}^{2}$ to $100 \mathrm{~W} / \mathrm{cm}^{2}$ ). The final insulator category is ablatives. Ablatives manage integrated heat loads by pyrolysis and are characterized by charring and surface recession. Ablators can be tailored to fit a more broad range of entry heat pulses and fit into higher heat pulse and duration entry scenarios (greater than 500 seconds, $75 \mathrm{~W} / \mathrm{cm}^{2}$ to $150 \mathrm{~W} / \mathrm{cm}^{2}$ ).

\section{Materials and Layups}

TPS coupons are made up of multiple material layers sandwiched together with thermocouples staggered through the thickness of the layup to avoid protuberances. Candidate TPS layups tested at the 8'HTT, PTF and LHMEL listed in Table 1, Table 2, and Table 3, respectively, were made up of materials listed in Table 4. PAIDAE-I, conducted in December 2007, 8'HTT test series materials and results have been previously documented and published in reference 5 .

Table 1. 8'HTT Candidate Layups from the PAIDAE-II Test Series

\begin{tabular}{|c|c|c|c|}
\hline Layup \# & Outer Fabrics & Insulators & Gas Barrier \\
\hline L1 & Nextel AF-14 & Pyrogel 6650 & 2x Kapton \\
\hline $\mathrm{L} 2$ & Nextel BF-20 & Pyrogel 6650 & 2x Kapton \\
\hline L3 & 2x Nextel AF-14 & 2x Pyrogel 3350 & 2x Kapton \\
\hline L4 & 2x Nextel BF-20 & 2x Pyrogel 3350 & 2x Kapton \\
\hline L5 & Refrasil UC100-28 & \begin{tabular}{l|l} 
KFA5 & Pyrogel 3350 \\
\end{tabular} & 2x Upilex \\
\hline
\end{tabular}


Table 2. PTF Flexible TPS Candidate Layups Tested in June 2010

\begin{tabular}{|c|c|c|c|}
\hline Layup \# & Outer Fabrics & Insulators & Gas Barrier \\
\hline L1 & 2x Nextel AF-14 & 2x Pyrogel 3350 & 2x Kapton \\
\hline $\mathrm{L} 2$ & 2x Nextel BF-20 & 2x Pyrogel 3350 & 2x Kapton \\
\hline $\mathrm{L} 3$ & Refrasil UC100-28 & 2x Pyrogel 3350 & 2x Kapton \\
\hline L4 & 2x Aerogel Impregnated BF-20 & 2x Pyrogel 3350 & 2x Kapton \\
\hline $\mathrm{L} 5$ & \begin{tabular}{|l|l} 
Nextel BF-20 & Aero-Impreg BF-20
\end{tabular} & $2 x$ Pyrogel 3350 & 2x Kapton \\
\hline
\end{tabular}

Table 3. LHMEL Flexible TPS Candidate Layups Tested in January 2010, April 2010, and September 2010

\begin{tabular}{|c|c|c|c|}
\hline Layup \# & Outer Fabrics & Insulators & Gas Barrier \\
\hline \hline L1 & 2x Nextel BF-20 & 2x Pyrogel 3350 & 1x Kapton \\
\hline L2 & 2x 5 Harness Satin (26x26) & 2x Pyrogel 3350 & 1x Kapton \\
\hline L3 & 2x 8 Harness Satin (30x26) & 2x Pyrogel 3350 & 1x Kapton \\
\hline L4 & 2x 8 Harness Satin (26x34) & 2x Pyrogel 3350 & 1x Kapton \\
\hline L5 & 2x 8 Harness Satin (1.5 layer) (26x30) & 2x Pyrogel 3350 & 1x Kapton \\
\hline L6 & 2x 8 Harness Satin (1.5 layer) (26x34) & 2x Pyrogel 3350 & 1x Kapton \\
\hline L7 & 2x 8 Harness Satin (double cloth) (26x30) & 2x Pyrogel 3350 & 1x Kapton \\
\hline L8 & 2x 8 Harness Satin (double cloth) (26x34) & 2x Pyrogel 3350 & 1x Kapton \\
\hline L9 & 2x 12 Harness Satin (2.5d) (40x40) & 2x Pyrogel 3350 & 1x Kapton \\
\hline L10 & 2x Nextel BF-20 & 2x Polyimide (6 mm) & 1x Kapton \\
\hline
\end{tabular}

Table 4. Flexible TPS Materials Description and General Information Outer Fabrics

\begin{tabular}{|c|c|}
\hline \multicolumn{2}{|r|}{ Outer Fabrics } \\
\hline Nextel AF-14 & $\begin{array}{l}3 \mathrm{M}^{\mathrm{TM}} \text { Nextel } \mathrm{TM} \text { Aerospace Fabrics } 312 \text { are woven from strong, continuous aluminoborosilicate } \\
\text { fibers. This fabric retains its strength, with little shrinkage, at continuous temperatures up to } \\
1100^{\circ} \mathrm{C} \text {. }\end{array}$ \\
\hline $\begin{array}{l}\text { Nextel BF-20 } \\
\text { and BF-10 }\end{array}$ & $\begin{array}{l}3 \mathrm{M}^{\mathrm{TM}} \text { Nextel } \mathrm{I}^{\mathrm{TM}} \text { Ceramic Fibers } 440 \text { are an aluminoborosilicate fiber that contains mullite crystals. } \\
\text { At } 2 \% \text { boria, these fibers contain less boria than Nextel }{ }^{\mathrm{TM}} \text { Ceramic Fibers } 312 \text {. These strong, } \\
\text { continuous fibers are woven into fabrics that retain strength with little shrinkage at continuous } \\
\text { temperatures up to } 1370^{\circ} \mathrm{C} \text {. }\end{array}$ \\
\hline SiC Weaves & $\begin{array}{l}\mathrm{SiC} \text { fabrics are a combination of } \mathrm{SiC} \text { fiber threads woven as } 5,8 \text {, and } 12 \text { harness satin fabrics. } \\
\text { Nicalon is a multi-filament silicon carbide-type fiber manufactured by Nippon Carbon Co., Ltd. of } \\
\text { Japan. The Nicalon fibers are derived from polycarbosilane. Polycarbosilane fibers are pyrolyzed } \\
\text { to achieve different compositions of } \mathrm{Si}: \mathrm{C}: \mathrm{O} \text { ratios. Commercial grades are type cg-Nicalon, Hi- } \\
\text { Nicalon and type } \mathrm{S} \text { Nicalon with the following } \mathrm{Si}: \mathrm{C}: \mathrm{O} \text { weight ratios: } 57: 32: 12,62: 37: 0.5 \text { and } \\
69: 31: 0.2 \text {. Nicalon tows are a bundle of } 500 \text { fibers. SiC fabrics have a maximum continuous use } \\
\text { temperature of } 1800^{\circ} \mathrm{C} \text {. }\end{array}$ \\
\hline $\begin{array}{l}\text { Refrasil UC100- } \\
28\end{array}$ & $\begin{array}{l}\text { REFRASIL standard woven fabric is known as the UC100 series cloth and is a acid-leached } \\
\text { amorphous silica. The silica content is at least } 96 \% \text {, which is necessary to obtain a temperature } \\
\text { resistance of } 982^{\circ} \mathrm{C}\end{array}$ \\
\hline \multicolumn{2}{|r|}{ Insulators } \\
\hline Pyrogel 3350 & $\begin{array}{l}\text { Pyrogel }{ }^{\circledR} \text { is a high-temperature flexible insulation blanket formed of silica aerogel and reinforced } \\
\text { with a non-woven, carbon- and glass-fiber batting. The maximum one time use temperature is } \\
1100^{\circ} \mathrm{C} \text {. }\end{array}$ \\
\hline $\begin{array}{c}\text { POSS Polyimide } \\
\text { aerogel }\end{array}$ & $\begin{array}{l}\text { Polyimide polyhedral oligomeric silsesquioxane (PI-POSS) aerogel is a high temperature flexible } \\
\text { insulation aerogel film with a 3-D network. The decomposition temperature is greater than } 560^{\circ} \mathrm{C} \text {. } \\
\text { The materials are expected to outgas carbon dioxide, ammonia, water vapor, and silica oxide. } \\
\text { There are no other known chemicals outgassed during the heating process. }\end{array}$ \\
\hline \multicolumn{2}{|r|}{ Gas Barrier } \\
\hline Kapton & $\begin{array}{l}\text { DuPont }{ }^{\mathrm{TM}} \text { Kapton } \AA \text { is polyimide film synthesized by polymerizing an aromatic di-anhydride with } \\
\text { an aromatic diamine. Kapton } \AA \text { can withstand temperatures as low as }-269^{\circ} \mathrm{C} \text { and as high as } 400^{\circ} \mathrm{C} \text {, } \\
\text { and still retain its properties, though at high temperatures, tensile performance decreases. }\end{array}$ \\
\hline
\end{tabular}

\section{Material Properties}

Accurate thermal model analytical results for a layered flexible TPS require that the thermophysical properties of each material layer of the flexible TPS be well characterized. In addition to the thermophysical properties of each 
material layer, the physical properties related to the engineering functional aspect of each material layer are also taken into account and drive material selection processes for each TPS layer. For an example of an engineering functional aspect selection; Saffil has a good conductivity ${ }^{10}$ at higher temperatures but has the consistency of cotton. If the outer layers of the flexible TPS fails, or develops a tear, a cotton-like insulation layer will not survive in a direct flow environment and could potentially result in a catastrophic loss of the vehicle. During reentry, outer fabrics experience shearing, pressure, and hot gas impingement resulting in high surface temperatures on the outer surface. Some critical aspects of the outer fabrics are the strength of the material after packing and deployment, permeability of the fabric which limits hot gas flow into the layup, and ability to withstand high temperatures as a result of convective heating, optical thickness, emissivity, and catalycity of the material. Insulators are positioned behind the outer fabrics, and will experience a small amount of shearing flow, but are required to reduce temperatures from outer fabrics to below the maximum usable temperature limits of the structural components. A desirable characteristic demonstrating robustness and fault tolerance of insulators, is a slow and graceful failure in the event that the outer fabrics fail resulting in the insulator being exposed directly to limited surface flow. Gas barrier materials are necessary to eliminate the potential for hot gas flow through the layup, but will not experience high temperatures, or shearing flow. The gas barrier layer ultimately will be attached directly to the structural components, so the gas barrier must be able to withstand a moderate level of heating.

Permeability is highly dependent on the weave architecture, fiber diameter, and weight of the fabric yarns. In order to accurately characterize the porosity of a given material, ASTM permeability tests were conducted on each outer fabric. Permeability is defined in ASTM Standard D-737-69 as the volume of air that can flow through 929 $\mathrm{cm}^{2}$ (one square foot) of cloth at a pressure drop of no more than $1.27 \mathrm{~cm}$ of water (125 Pa), illustrated in Figure 13. Permeability measurements were performed by Cosmotica Corporation and ILC Dover. All measurements shown in Figure 14 were made with fabric sizing on the fibers.

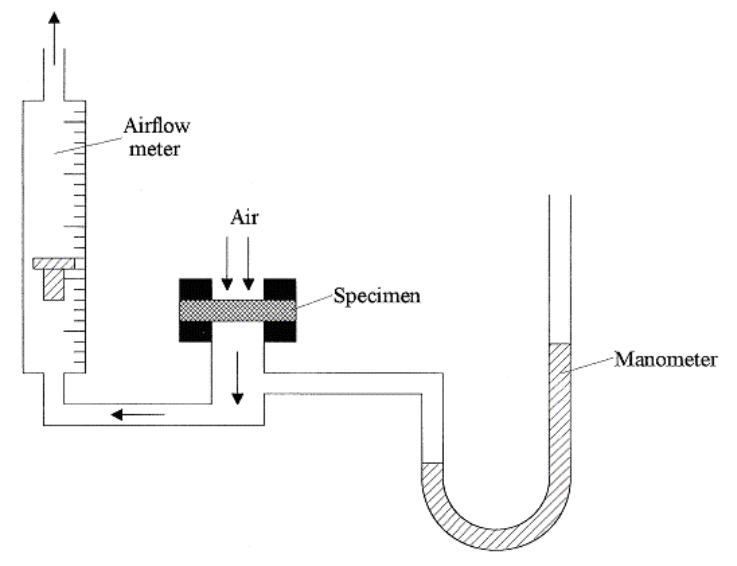

Figure 13. Schematic of ASTM Standard D-737-69 air permeability measurement annaratus.

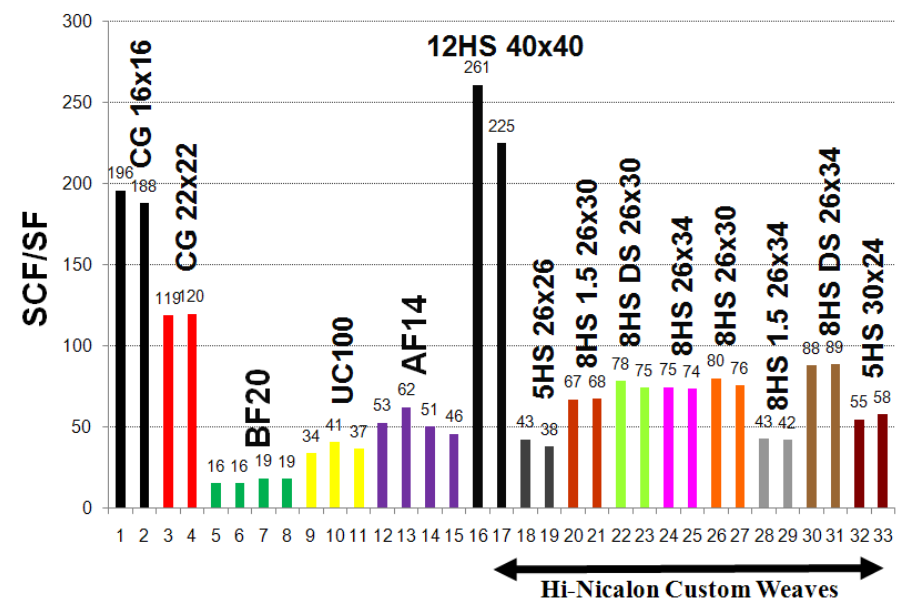

Figure 14. Permeability of candidate flexible TPS outer fabrics. 
Outer fabric fibers were more brittle than insulator or gas barrier materials. The fiber brittleness limits the ability to pack an aeroshell, and therefore was important to quantify strength reduction as a result of damage due to stowage resulting from different bend radii. Single yarn tow and 10 tow fabric breaking loads were measured for BF-20 and Hi-Nicalon materials, on an Instron test machine at room temperature are shown in Figure 15 and Figure 16 , respectively. Tensile testing was performed with a $1 \mathrm{kN}$ load cell with a crosshead speed of $0.01722 \mathrm{~mm} / \mathrm{min}$. Sizing was not removed from the fabrics and tows, and fabric samples contained 10 tows. Samples were folded over cylindrical templates having diameters of $0.635 \mathrm{~cm}, 0.317 \mathrm{~cm}, 0.158 \mathrm{~cm}$, and also folded on itself without a cylindrical template. The peak force to cause failure was then recorded on the samples. ${ }^{11}$

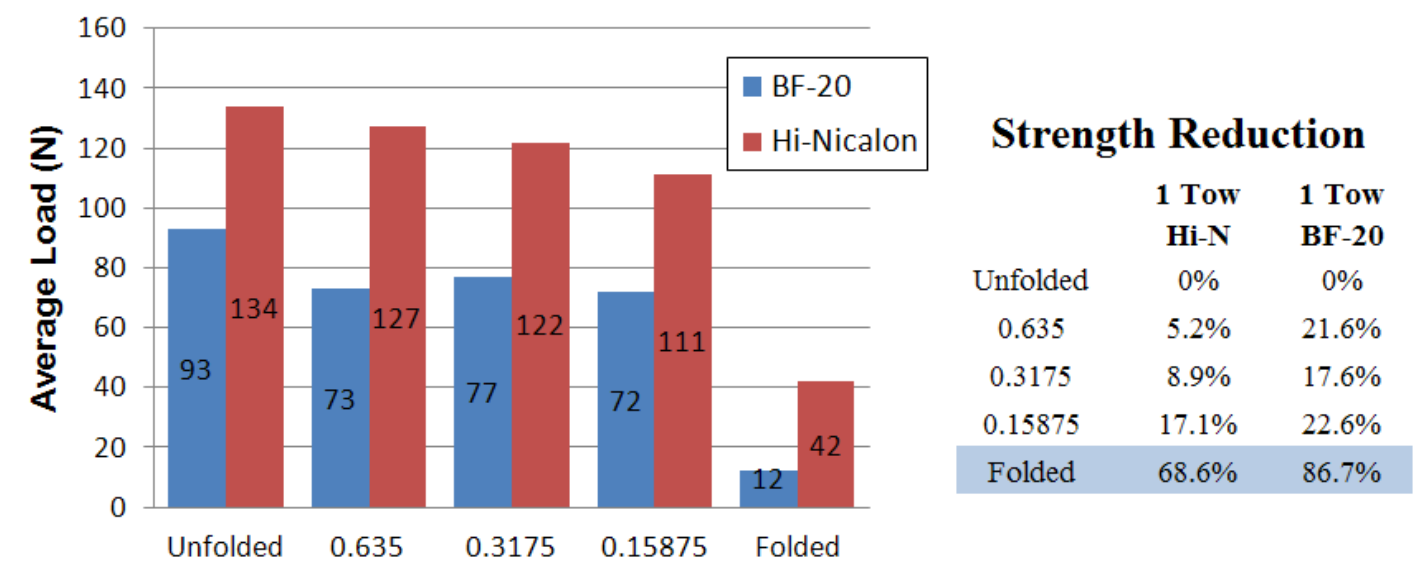

Mandrel Radius (cm)

Figure 15. SiC single tow average breaking force vs. bend radius (left) and strength reduction (right).

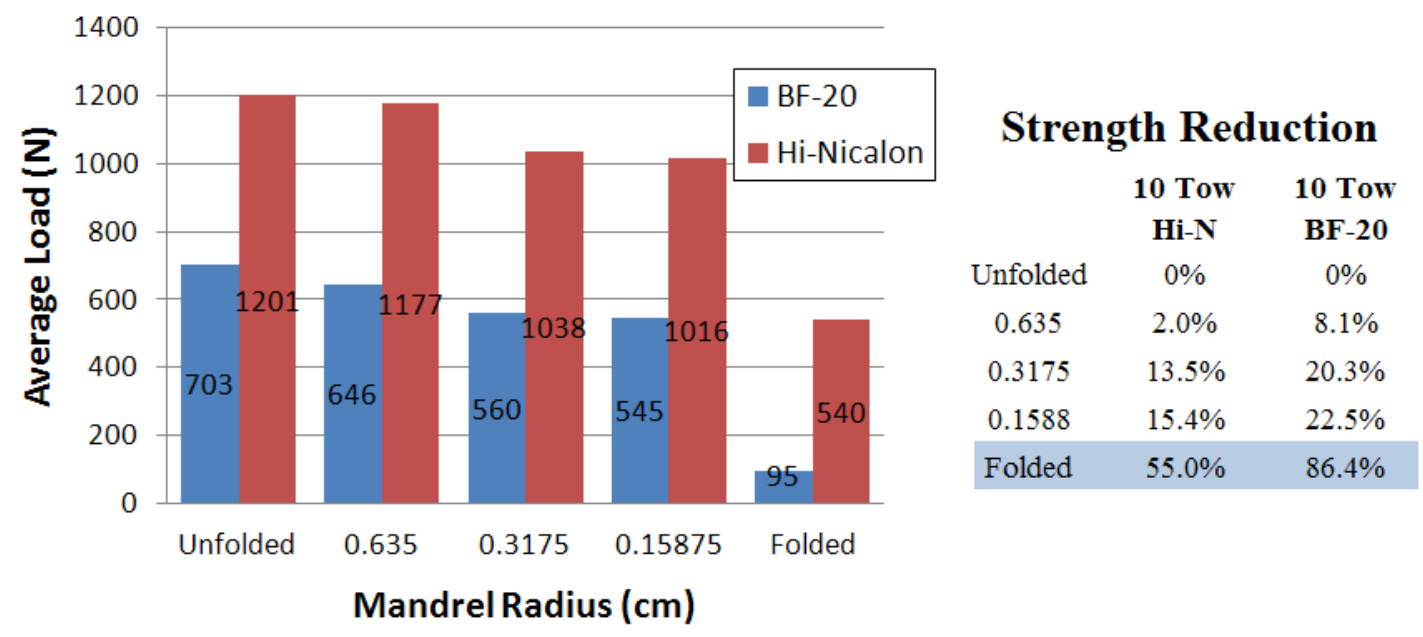

Figure 16. SiC 10 tow average breaking force vs. bend radius (left) and strength reduction (right).

The original baseline insulator material tested was a Pyrogel 6650, during the PAIDAE test series. The material performed well, but suffered from excessive particulation and redistribution of aerogel within the insulation batting after handling. Pyrogel 3350, initially believed to be a much lower temperature insulating material, was discovered to be capable of sustaining significantly higher temperatures than expected, when during a run the outer fabric and outer insulator layers of the layup sheared away, exposing the Pyrogel 3350 backing insulator directly to Mach 7 flow for duration of nearly 70 seconds. Manufacturer-supplied data sheets indicated a maximum usable temperature of $385^{\circ} \mathrm{C}$. Discussions with the manufacturer revealed that the original intended use of Pyrogel 3350 was as heat pipe insulation for factories, and that the maximum continuous use temperature is representative of extended use and 
exposure to the elements for durations of 10 years to 20 years. The manufacturer indicated that for durations of 5 minutes to 10 minutes, the material could easily survive temperatures of $1100^{\circ} \mathrm{C}$.

Pyrogel 3350 is made up of $70 \%$ oxidized polyacrilonitrile (OPAN) batting impregnated with an inorganic aerogel. Pyrogel 3350 was initially believed to be a fully insulative material. PTF ground tests revealed that Pyrogel 3350 outgasses water and hydrocarbons, shown in the graph in Figure 17, which are the manufacturing byproducts used to bond the inorganic aerogel to the OPAN batting. Effectively, the material becomes 'active' (outgases) between approximately $375^{\circ} \mathrm{C}$ to $600^{\circ} \mathrm{C}$, and experiences a $15 \%$ weight reduction shown in Figure 18 . Thermogravimetric analysis (TGA) and Fourier transform infrared radiometry (FTIR) analysis was used to quantify outgassing components of Pyrogel 3350, at GRC.

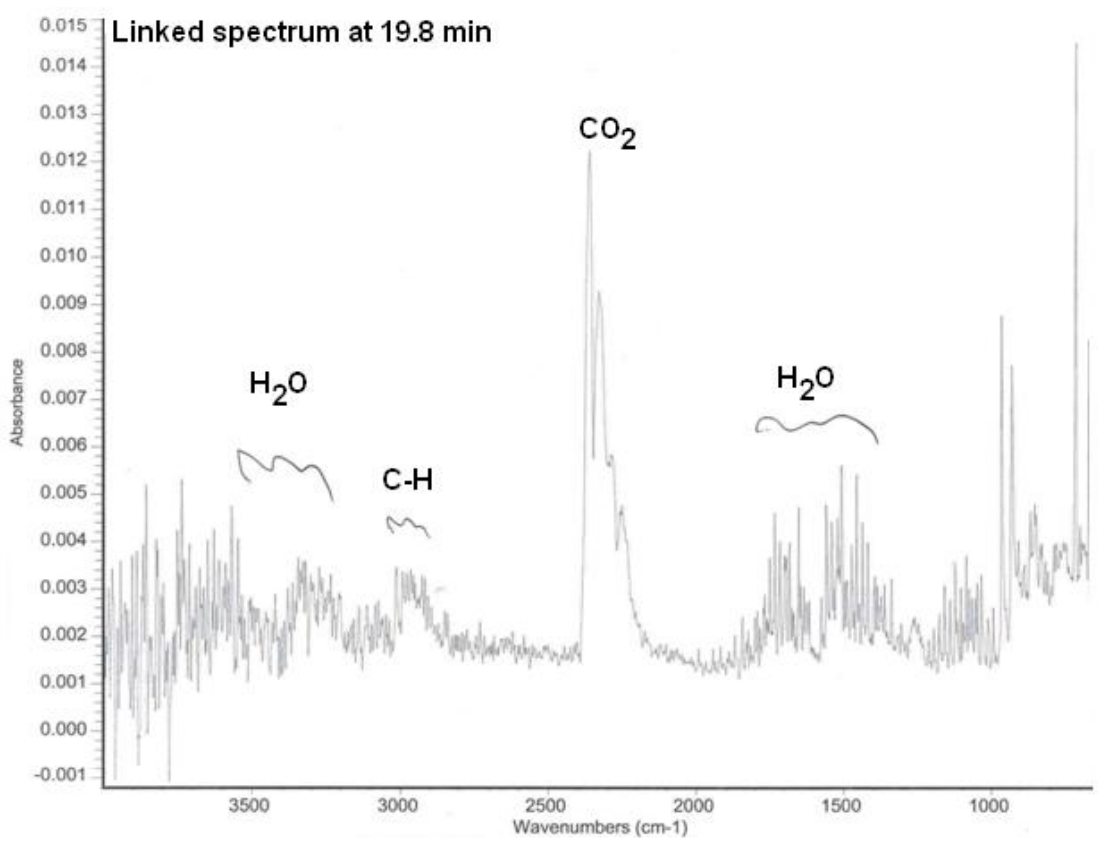

Figure 17. FTIR of active Pyrogel 3350 at approximately $375^{\circ} \mathrm{C}$.

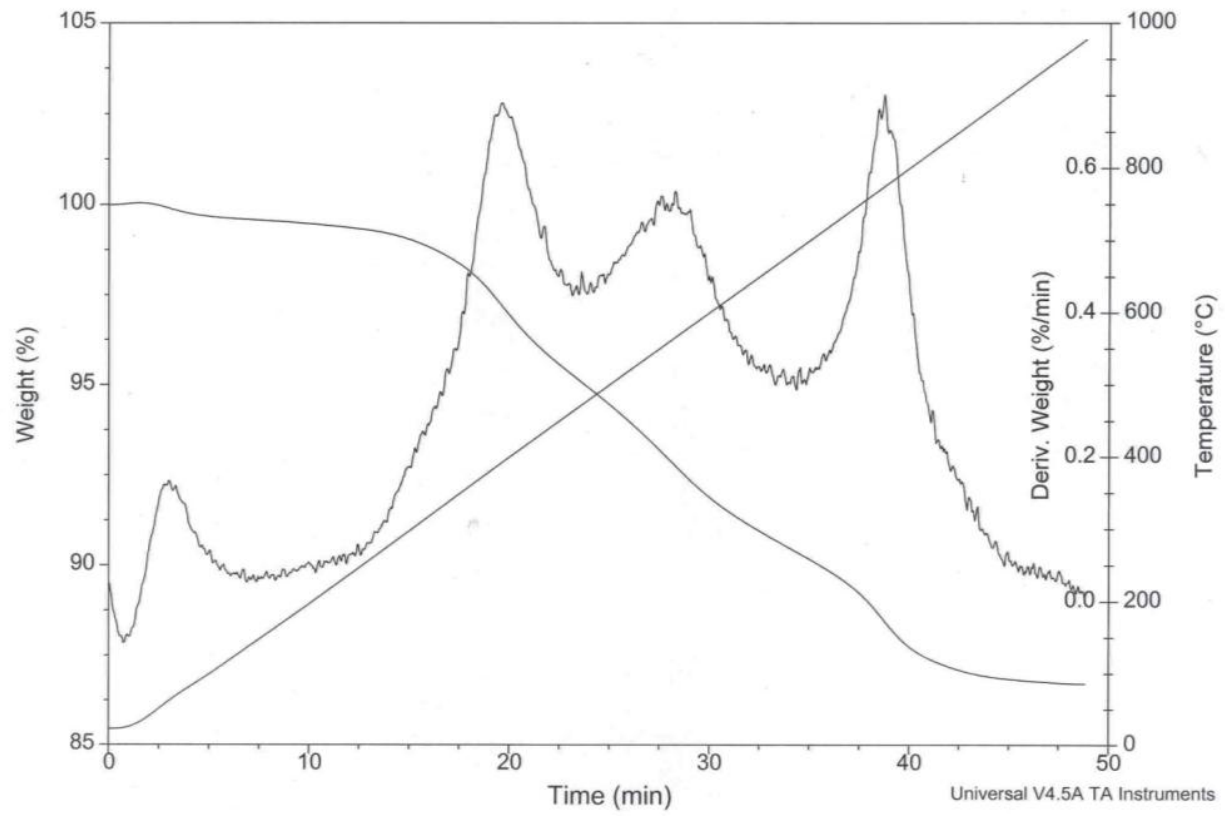

Figure 18. TGA of Pyrogel 3350 from room temperature to $950^{\circ} \mathrm{C}$. 
Insulator materials are necessary to reduce the temperature of outer fabrics to usable structural temperatures. In Figure 19 a comparison of temperature versus insulator conductivities in vacuum for Pyrogel 3350 and PI-POSS polyimide $^{12}$ to standard Saffil materials at densities of $48 \mathrm{~kg} / \mathrm{m}^{3}, 96 \mathrm{~kg} / \mathrm{m}^{3}$, and $144 \mathrm{~kg} / \mathrm{m}^{3}$ densities is shown ${ }^{10}$.

Saffil was originally considered as a viable candidate due to the excellent thermal conductivity of Saffil as the temperature of the material increases, but was rejected due to manufacturer's minimum gage thickness of $12 \mathrm{~mm}$, and because the material had very low tensile strength. With a low tensile strength, Saffil would mechanically fail at the exposure to any shearing flow. Additional material information is provided in Table 5, for outer fabrics, insulators and gas barrier materials.

PI-POSS aerogel is a high temperature flexible insulation aerogel film with a 3-dimensional (3-D) network; polyimide crosslinked by octa (aminophenyl). The decomposition temperature is greater than $560^{\circ} \mathrm{C}$. The materials outgas carbon dioxide, ammonia, water vapor, and silica oxide. These transpiring-insulators are part of a development effort being conducted by GRC.

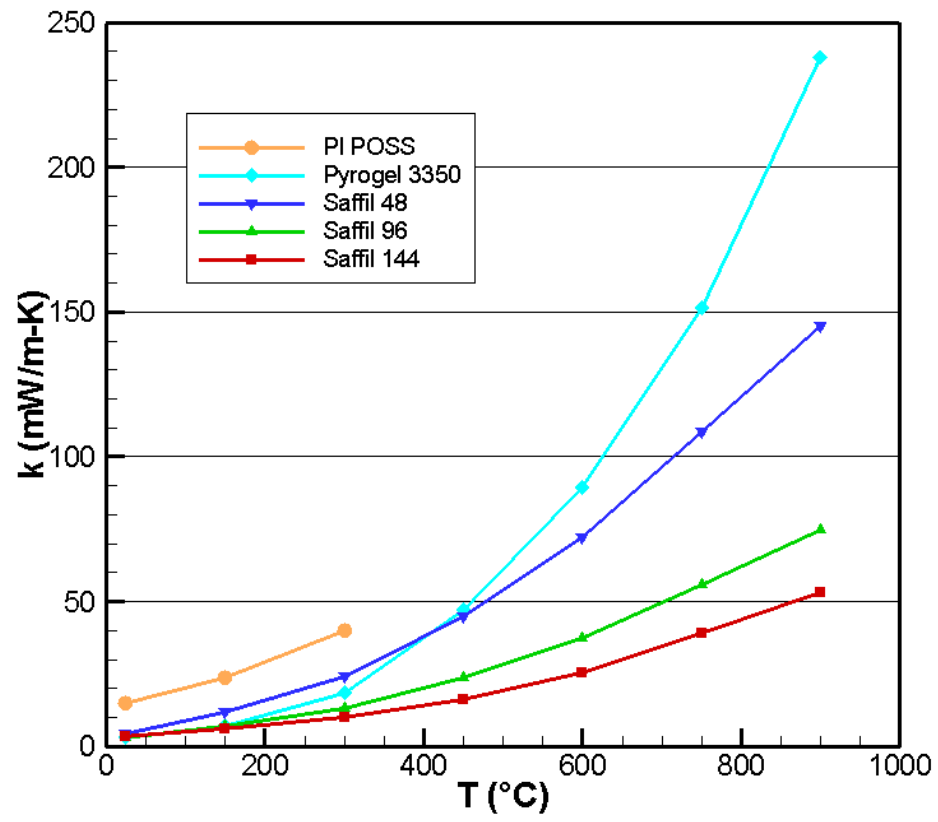

Figure 19. Flexible TPS temperature dependent insulator conductivities in vacuum.

\section{Thermal Model and Tools}

TPS candidate layups were analytically modeled to estimate the thermal performance and to assist in the down select process for determining potential layups for testing. Results from initial 3-D analysis, using Patran Thermal ${ }^{\circledR}$ and Thermal Desktop ${ }^{\circledR}$, indicated that a 1-dimensional (1-D) analysis was sufficient for determining the thermal performance as long as the areas of interest were approximately $2.54 \mathrm{~cm}$ from the edge of the sample holder frame. For all of the ground based testing efforts, the particular areas of interest on the test samples are located towards the center of the sample, which in all cases is more than 1-inch from the sample holder edges. Therefore, 1-D analysis has been used for all the thermal analytical calculations.

The thermal model was originally developed for the first IRVE Program and was modeled as a conduction heat transfer process ignoring radiation effects through the layup. The original IRVE heating profile was relatively low and the TPS layup did not have insulating layers, only three layers of Nextel 312 fabric and a gas barrier of Kapton and Kevlar layers. The thermal properties of this particular layup were measured and the contact conductance between the individual fabric layers was estimated as a function of compression pressure and atmospheric pressure. $^{13}$ 
Table 5. Flexible TPS Material Thicknesses, Areal Weight, and Maximum Use Temperatures

\begin{tabular}{|l|c|c|c|}
\hline Material & $\begin{array}{c}\text { Thickness } \\
(\mathbf{c m})\end{array}$ & $\begin{array}{c}\text { Areal Weight } \\
\left(\mathbf{g} / \mathbf{c m}^{\mathbf{2}}\right)\end{array}$ & $\begin{array}{c}\text { Maximum Use } \\
\text { Temperature } \\
\left({ }^{\circ} \mathbf{C}\right)\end{array}$ \\
\hline Nextel BF-20 & 0.0508 & 0.0505 & 1375 \\
\hline Nextel BF-10 & 0.0254 & 0.0265 & 1375 \\
\hline 5 Harness Satin (26x26) & 0.0506 & 0.0425 & 1800 \\
\hline 8 Harness Satin (30x26) & 0.0560 & 0.0431 & 1800 \\
\hline 8 Harness Satin (26x34) & 0.0620 & 0.0471 & 1800 \\
\hline 8 Harness Satin (1.5 layer) (26x30) & 0.0607 & 0.0443 & 1800 \\
\hline 8 Harness Satin (1.5 layer) (26x34) & 0.0604 & 0.0459 & 1800 \\
\hline 8 Harness Satin (double cloth) (26x30) & 0.0586 & 0.0428 & 1800 \\
\hline 8 Harness Satin (double cloth) (26x34) & 0.0608 & 0.0462 & 1800 \\
\hline 12 Harness Satin (2.5 d) (40x40) & 0.1142 & 0.0628 & 1800 \\
\hline Pyrogel 3350 & 0.3047 & 0.0518 & 1100 \\
\hline PI-POSS Aerogel & 0.0614 & 0.0068 & 500 \\
\hline Kapton & 0.0025 & 0.0037 & 350 \\
\hline
\end{tabular}

Newer TPS concepts incorporated insulating layers to endure the higher heating rates. It was not expected that the contact conductance measurements obtained for the Nextel-only layups would be accurate for layups with insulating layers, and subsequent tests in the 8'HTT validated this assumption. The contact resistance that had been modeled between each layer of material was now considered a thermal resistance between each layer, as shown in Figure 20, and was used to empirically fit the model to the test data.

The thermal model has been empirically fit to the IRVE-3 baseline TPS layup for heating fluxes between $5 \mathrm{~W} / \mathrm{cm}^{2}$ to $20 \mathrm{~W} / \mathrm{cm}^{2}$. However, since the model does not capture all of the physical phenomena there is little confidence in using this model to determine the thermal performance for any other layups or heating rates. In addition, the Pyrogel insulating material used in the IRVE-3 TPS is an active material that chars and outgases at temperatures above approximately $350^{\circ} \mathrm{C}$ and there was no effort to capture the physics of this process in the thermal model.

An effort is under way to substantially improve the thermal modeling methods with the development of a physics-based model. This new model will capture the physical phenomena of the materials including the active state of the Pyrogel or any other active type of materials

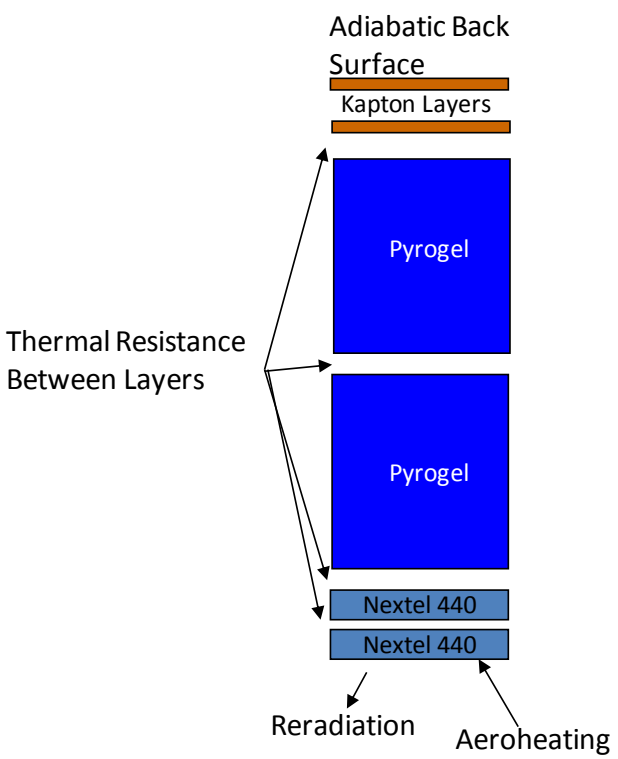

Figure 20. 1-D diffusion based thermal model concept.

that might be considered. This effort is first focused on obtaining accurate thermal property measurements of the various TPS materials at relevant temperature and pressures including optical and radiant transmission data. Once accurate thermal properties have been acquired, thermal models will be developed and compared with test data from high-temperature tunnel tests and laboratory type thermal tests. 


\section{Thermal Loads and Boundary Conditions}

TPS tests conducted at the 8'HTT were subjected to several heating and mechanical loading conditions. Sample test conditions were achieved by changing combustor pressure and temperatures, and varying the sled angle of attack (AOA). Sample tests were conducted at combustor temperature of $1560^{\circ} \mathrm{C}$ and at combustor pressures of $760 \mathrm{psi}$ and $1440 \mathrm{psi}$, which correspond to relatively low and high surface pressure conditions. Free stream properties for relatively low and high pressure conditions include Mach 6.5 to Mach 6.35, pressure of 0.117 psia to 0.236 psia, temperatures of $388 \mathrm{R}$ to $417 \mathrm{R}$. These combustor temperatures and pressures, combined with a sled AOA of $-5^{\circ}$, resulted in square pulse cold wall heat flux ${ }^{14}$ of $6 \mathrm{~W} / \mathrm{cm}^{2}$ to $20 \mathrm{~W} / \mathrm{cm}^{2}$ (Table 8). Nominal facility flow species composition consists of mole fractions of $58 \%$ nitrogen $\left(\mathrm{N}_{2}=0.5884\right), 20 \%$ oxygen $\left(\mathrm{O}_{2}=0.2028\right), 6 \%$ carbon dioxide $\left(\mathrm{CO}_{2}=0.0675\right), 13 \%$ water $\left(\mathrm{H}_{2} \mathrm{O}=0.1344\right)$, and $0.7 \%$ argon $(\mathrm{Ar}=0.007)$. For each run, samples were flushmounted to the sled surface. The sled was retracted from the flow while the facility was started and hypersonic flow was established in the test chamber. The sled was then inclined to $-5^{\circ}$ AOA and injected into the flow for duration of 90 seconds. After 90 seconds the sled was retracted from the flow and the facility initiated a normal stop (combustor off, cold air blow down).

Table 6. 8'HTT Facility Run Conditions

\begin{tabular}{|l|c|c|}
\hline Units & $\begin{array}{c}\text { Low Pressure } \\
\text { Condition }\end{array}$ & $\begin{array}{c}\text { High Pressure } \\
\text { Condition }\end{array}$ \\
\hline Mach (\#) & 6.5 & 6.35 \\
\hline Pressure (psia) & 0.117 & 0.2355 \\
\hline Temperature (R) & 387.6 & 416.7 \\
\hline Velocity (ft/s) & 6273.9 & 6385 \\
\hline
\end{tabular}

TPS tests conducted at PTF were subjected to several heating conditions and mechanical loading conditions. Sample test conditions were achieved by setting arc current and air mass flow rate, and by setting the sample plate AOA. Sample tests were conducted at heat fluxes of $16 \mathrm{~W} / \mathrm{cm}^{2}, 24 \mathrm{~W} / \mathrm{cm}^{2}$, and $30 \mathrm{~W} / \mathrm{cm}^{2}$, and facility settings listed in Table 7.

Table 7. PTF Facility Run Conditions

\begin{tabular}{|c|c|c|c|}
\hline $\begin{array}{c}\text { Heat Flux } \\
\left(\mathbf{W} / \mathbf{c m}^{\mathbf{2}}\right)\end{array}$ & $\begin{array}{c}\text { Arc Current } \\
(\mathbf{a m p s})\end{array}$ & $\begin{array}{c}\text { Air Mass Flow Rate } \\
(\mathbf{g} / \mathbf{s e c})\end{array}$ & $\begin{array}{c}\text { TPS AOA } \\
(\mathbf{d e g})\end{array}$ \\
\hline 16 & 1793 & 220 & -2 \\
\hline 24 & 1795 & 220 & 2 \\
\hline 30 & 1990 & 250 & 3 \\
\hline
\end{tabular}

TPS tests conducted at LHMEL were subjected to several heating conditions and pressure environments. Test conditions were achieved by setting the power output of the laser to produce a target heat rate over a $30.7 \mathrm{~cm}^{2}$ area, and vacuum pumps were used to achieve target pressures in the vacuum chamber. Within the vacuum chamber, a minimal $\mathrm{N}_{2}$ gas clearing flow was applied across the sample surface, and dry air was used across the laser window surface, in order to prevent ejecta from plating out onto optical surfaces. Vacuum pumps were calibrated to keep constant pressure within the vacuum chamber with the clearing flows. Samples were tested at ambient pressures of 8 torr, 50 torr, and 80 torr, and heat fluxes of $20 \mathrm{~W} / \mathrm{cm}^{2}, 35 \mathrm{~W} / \mathrm{cm}^{2}, 50 \mathrm{~W} / \mathrm{cm}^{2}$, and $100 \mathrm{~W} / \mathrm{cm}^{2}$. Only the baseline TPS was tested at the 8'HTT, LHMEL, and PTF and are listed in Table 8. SiC and PI-POSS based TPS were tested only at LHMEL. The SiC layup was tested with a $100 \mathrm{~W} / \mathrm{cm}^{2}$ incident heat flux from the LHMEL-I laser for a period of 90 seconds, and also at $50 \mathrm{~W} / \mathrm{cm}^{2}$ incident heat flux from the LHMEL-I laser for a period of 200 seconds. 
Table 8. Facility Thermal Loads and Boundary Conditions of the Baseline TPS

\begin{tabular}{|c|c|c|c|c|c|}
\hline Facility & $\begin{array}{c}\text { Sample Size } \\
\left(\mathrm{cm}^{2}\right)\end{array}$ & $\begin{array}{c}\text { Surface Pressure } \\
(\mathrm{kPa})\end{array}$ & $\begin{array}{c}\text { Heat Flux } \\
\left(\mathrm{W} / \mathrm{cm}^{2}\right)\end{array}$ & $\begin{array}{c}\text { Duration } \\
\text { (sec) }\end{array}$ & $\begin{array}{c}\text { Heat Load } \\
\left(\mathrm{J} / \mathrm{cm}^{2}\right)\end{array}$ \\
\hline \multirow{4}{*}{ 8'HTT } & \multirow{4}{*}{155} & 2 & 6 & $\begin{array}{l}90 \\
\end{array}$ & 54540 \\
\hline & & 3 & 11 & 90 & 990 \\
\hline & & 6 & 15 & 90 & 1350 \\
\hline & & 9.1 & 18 & 90 & 1620 \\
\hline \multirow{4}{*}{ LHMEL } & \multirow{4}{*}{103} & NA & 16 & 90 & 1440 \\
\hline & & NA & 20 & 90 & 1800 \\
\hline & & NA & 30 & 90 & 2700 \\
\hline & & NA & 37.5 & 120 & 4500 \\
\hline \multirow{3}{*}{ PTF } & \multirow{3}{*}{103} & 0.95 & 16 & 70 & 1120 \\
\hline & & 1.4 & 24 & 70 & 1680 \\
\hline & & 1.7 & 30 & 70 & 2100 \\
\hline
\end{tabular}

\section{Results}

Even though it is not feasible to document the results of all layups tested in the paper, there are three principal layups which are important. The baseline TPS for IRVE-3 was tested at the $8^{\prime} \mathrm{HTT}$ at a heat flux of $16 \mathrm{~W} / \mathrm{cm}^{2}$ with the result plotted in Figure 21 at LHMEL at a heat flux of $20 \mathrm{~W} / \mathrm{cm}^{2}$ for 90 seconds with the result plotted in Figure 22, and at PTF at a heat flux of $24 \mathrm{~W} / \mathrm{cm}^{2}$ for 70 seconds with the result plotted in Figure 23. The results are plotted with both the calculated thermal analysis (dashed lines) and measured thermocouple (solid lines) temperatures. The baseline TPS, as, is made up of two layers of Nextel BF-20, two layers of Pyrogel 3350, and two layers of Kapton. BF-20 is a Nextel 4405 harness satin, 2000 denier roving yarn material. The baseline TPS tested in the 8'HTT and LHMEL were instrumented with thermocouples between each of the materials, starting behind the top two Nextel 440 layers and ending between the bottom Pyrogel 3350 layer and the top Kapton layer. The baseline TPS tested in the PTF arcjet facility were instrumented with thermocouples (TC) between the Nextel 440-Pyrogel 3350 interface, between the Pyrogel 3350-Pyrogel 3350 interface, and the Pyrogel 3350-Kapton interface.

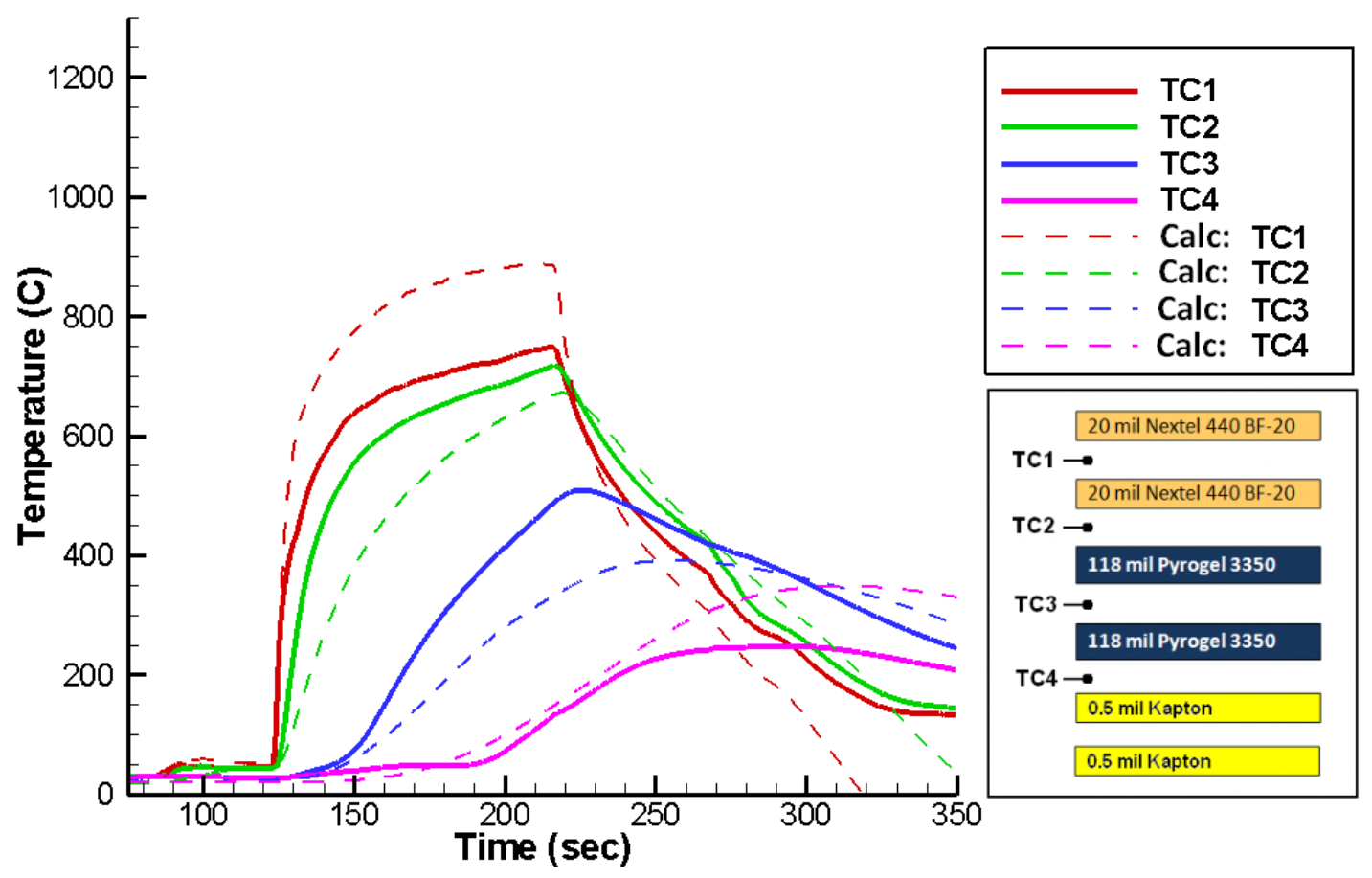

Figure 21. 8'HTT thermocouple temperature measurements (solid) and calculated temperature results (dashed) at various layers for the baseline TPS test at heat flux of $16 \mathrm{~W} / \mathrm{cm}^{2}$ for 90 seconds. 


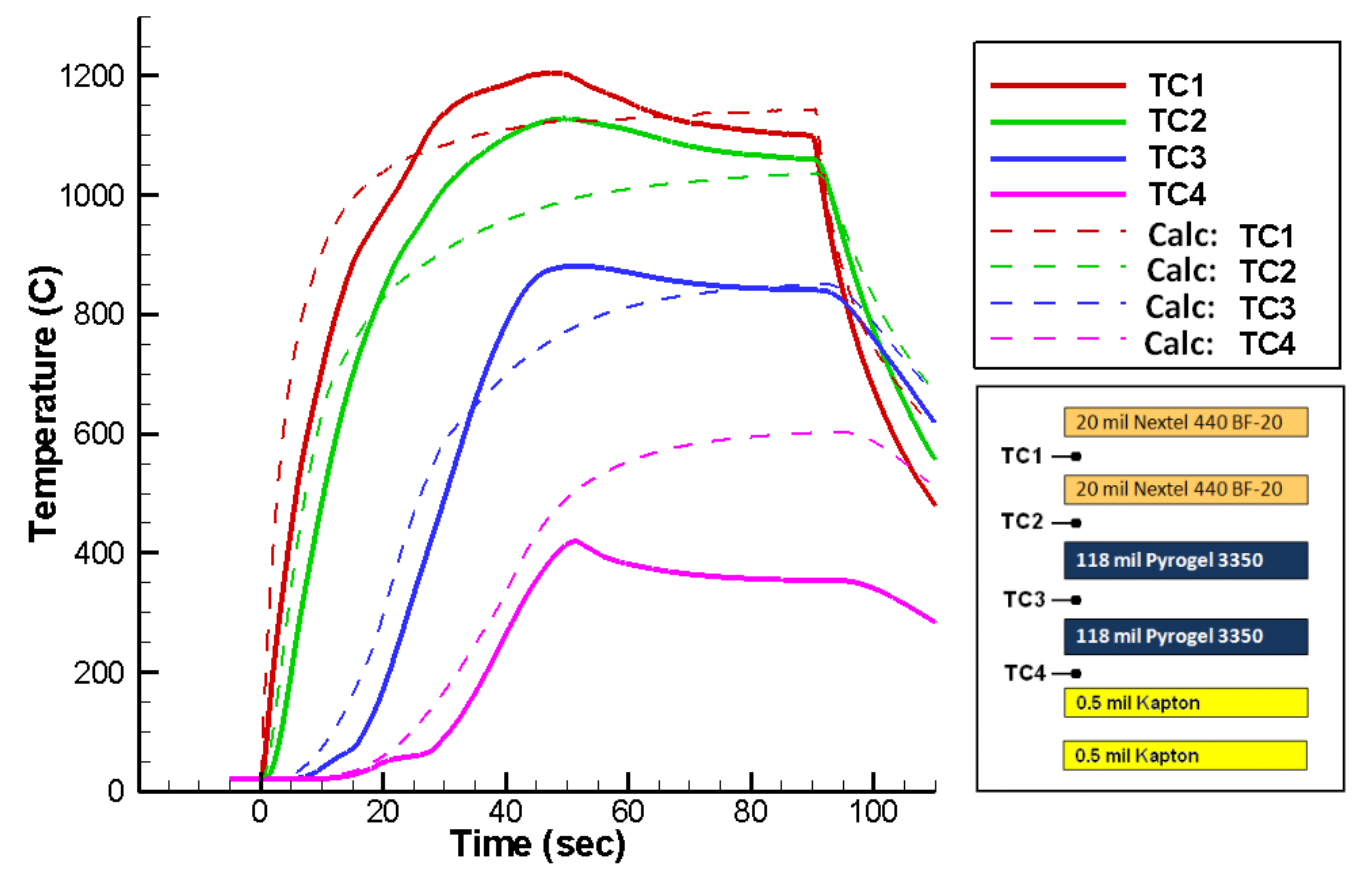

Figure 22. LHMEL thermocouple temperature measurements (solid) and calculated temperature results (dashed) at various layers for the baseline TPS test at a heat flux of $20 \mathrm{~W} / \mathrm{cm}^{2}$ for 90 seconds.

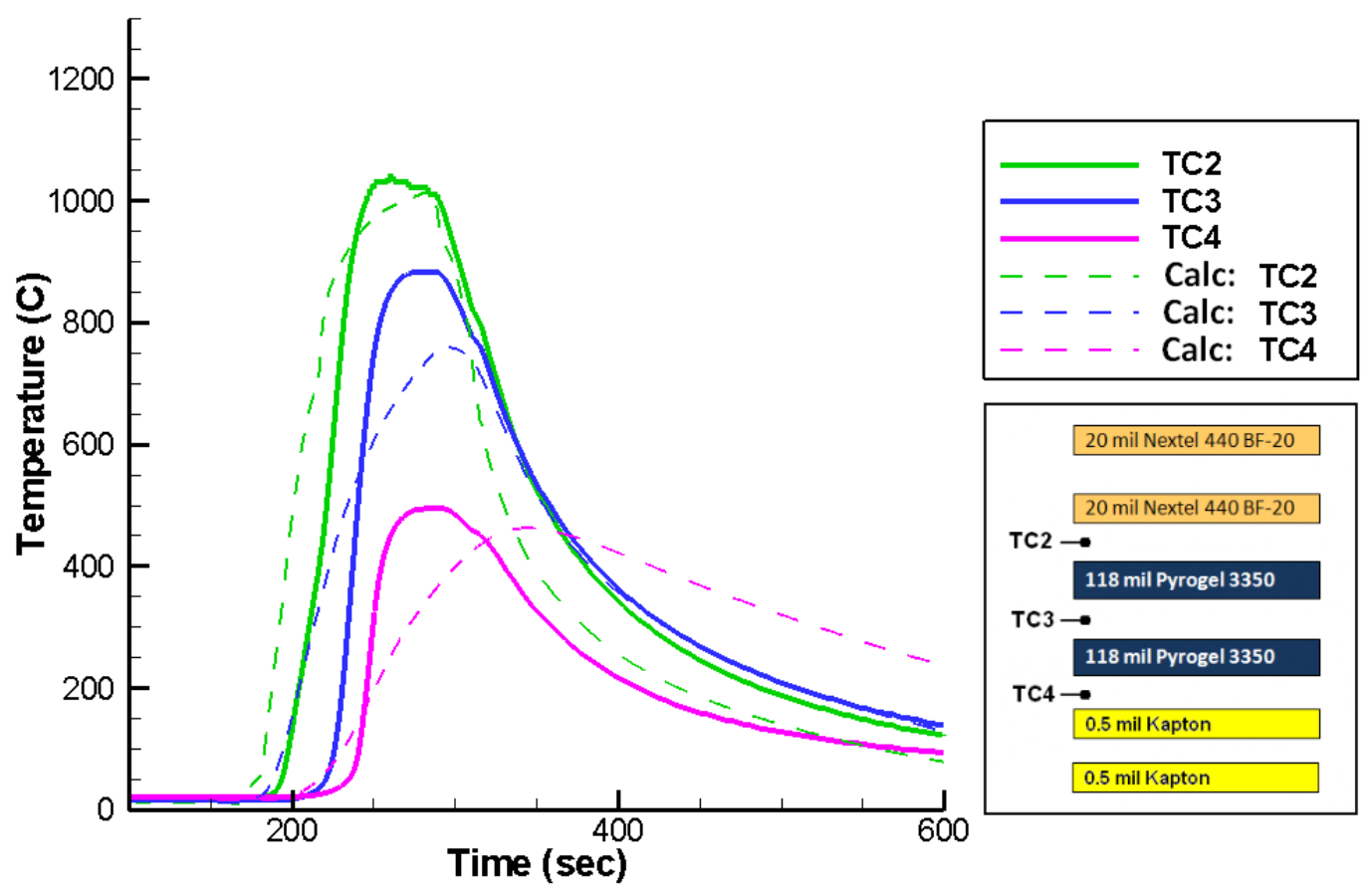

Figure 23. PTF thermocouple temperature measurements (solid) and calculated temperature results (dashed) at various layers for the baseline TPS test at a heat flux of $24 \mathrm{~W} / \mathrm{cm}^{2}$ for 70 seconds. 
The results for the baseline TPS at the IRVE-3 heating rates indicates that all material layers survived the square pulse heat flux. Relative to previously discussed trajectory profiles, the ground tested TPS subjected to $16 \mathrm{~W} / \mathrm{cm}^{2}$ to $24 \mathrm{~W} / \mathrm{cm}^{2}$ heat rates for 70 seconds to 90 seconds periods are an over-test of the TPS, since the integrated heat load is much higher than would otherwise be experienced in flight.

Two second-generation TPS tests were conducted at LHMEL in order to evaluate GRC-developed polyimide insulators, and $\mathrm{SiC}$ outer fabric weaves. The polyimide layup consists of two layers of Nextel BF-20 outer fabric, eleven layers of $0.60 \mathrm{~mm}$ thick PI-POSS polyimide insulator material, and two layers of Kapton gas barriers. The $\mathrm{SiC}$ layup consists of the 5 harness satin 26 by 26 (warp by fill) weave outer fabric, two layers of Pyrogel 3350 insulators, and two layers of Kapton gas barrier. Outer fabric temperatures were measured with a multicolor pyrometer.

The result plotted in Figure 24 of a laser heat flux load of $20 \mathrm{~W} / \mathrm{cm}^{2}$ for 90 seconds on the polyimide TPS, doesn't show the burn through that occurred. The polyimide insulator has a maximum temperature of $500^{\circ} \mathrm{C}$, with the onset of decomposition occurring at greater than $560^{\circ} \mathrm{C}$. Inspection of the decompiled sample following the LHMEL test revealed the outer polyimide materials were charred and showed signs of the onset of decomposition on the first seven polyimide layers. While charring appeared on all subsequent layers, there was not the same decomposition and burn through of material as seen in the first seven layers of the layup. Due to PI-POSS relatively low usable temperature range $\left(0^{\circ} \mathrm{C}\right.$ to $\left.500^{\circ} \mathrm{C}\right)$, the PI-POSS should be used as a backing material to a higher temperature capable insulator, such as the Pyrogel 3350. Results are presented with only measured thermocouple data and not calculated temperatures, since reliable thermophysical and optical properties were not well defined by the time this paper was written.
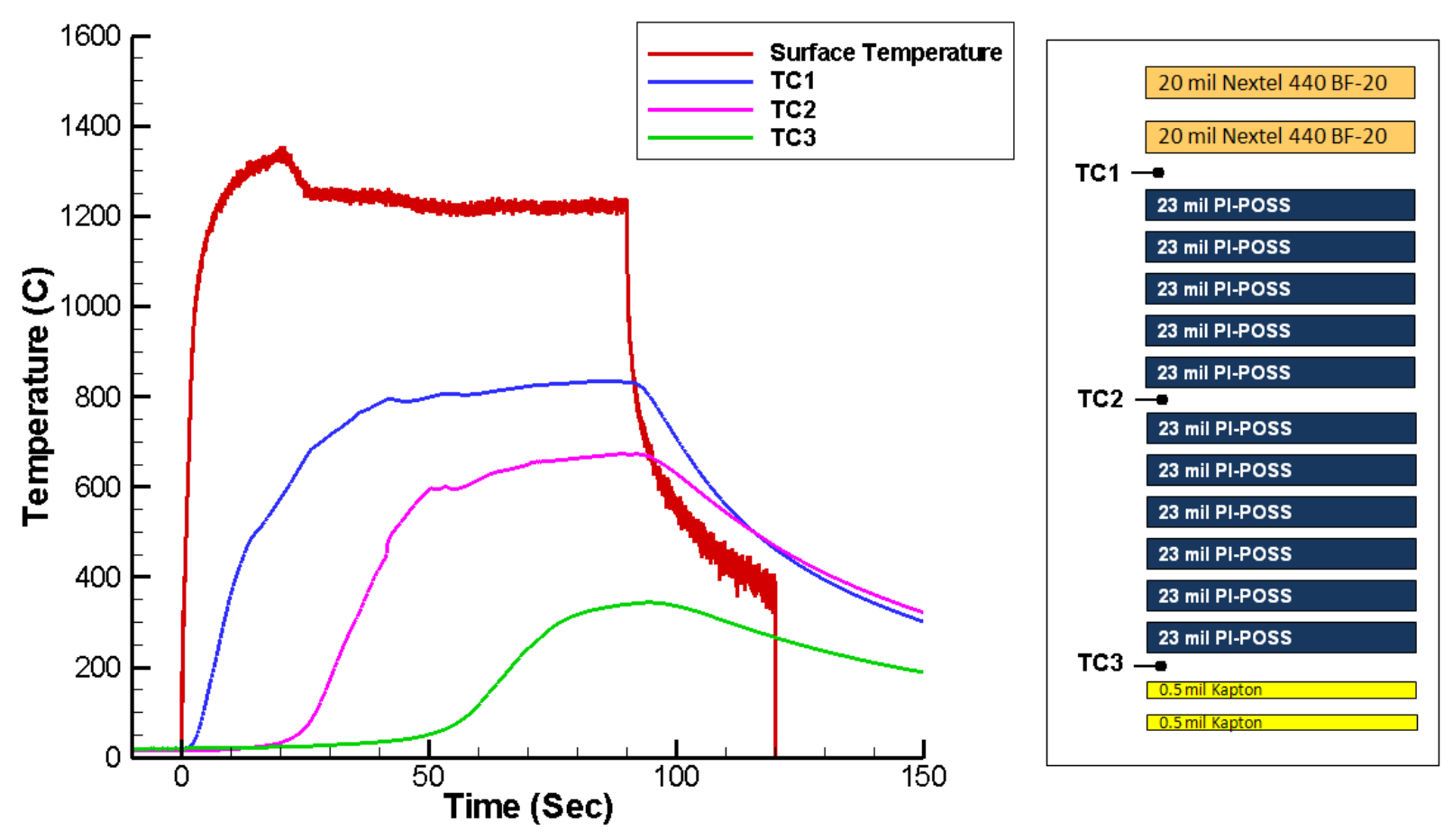

Figure 24. LHMEL thermocouple temperatures at various layers for the PI-POSS layup tested at a heat flux of $20 \mathrm{~W} / \mathrm{cm}^{2}$ and pressure of 8 torr for 90 seconds. 


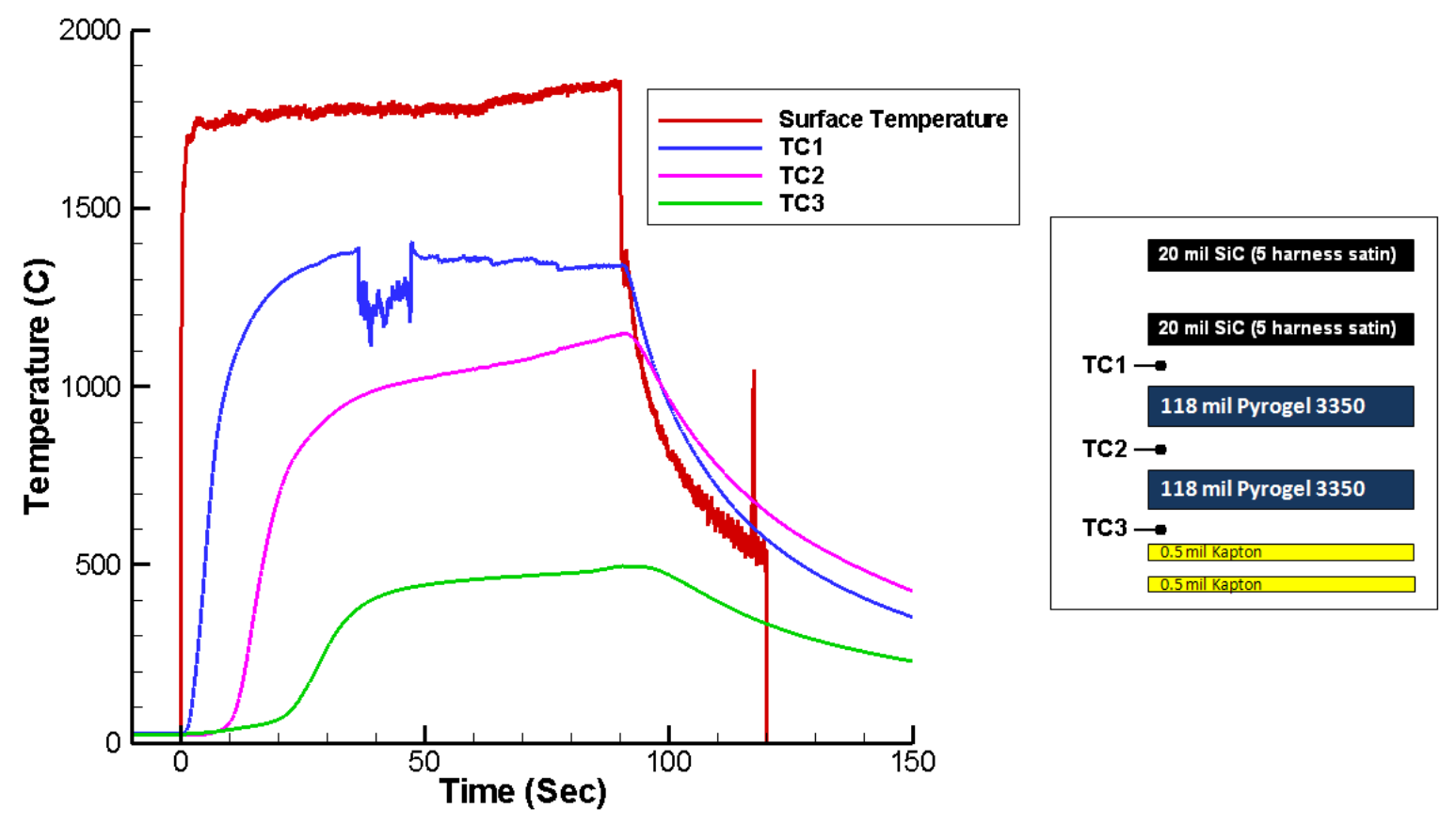

Figure 25. LHMEL thermocouple temperatures at various layers for the SiC 5HS layup tested at a heat flux of $100 \mathrm{~W} / \mathrm{cm}^{2}$ and pressure of 8 torr for 90 seconds.

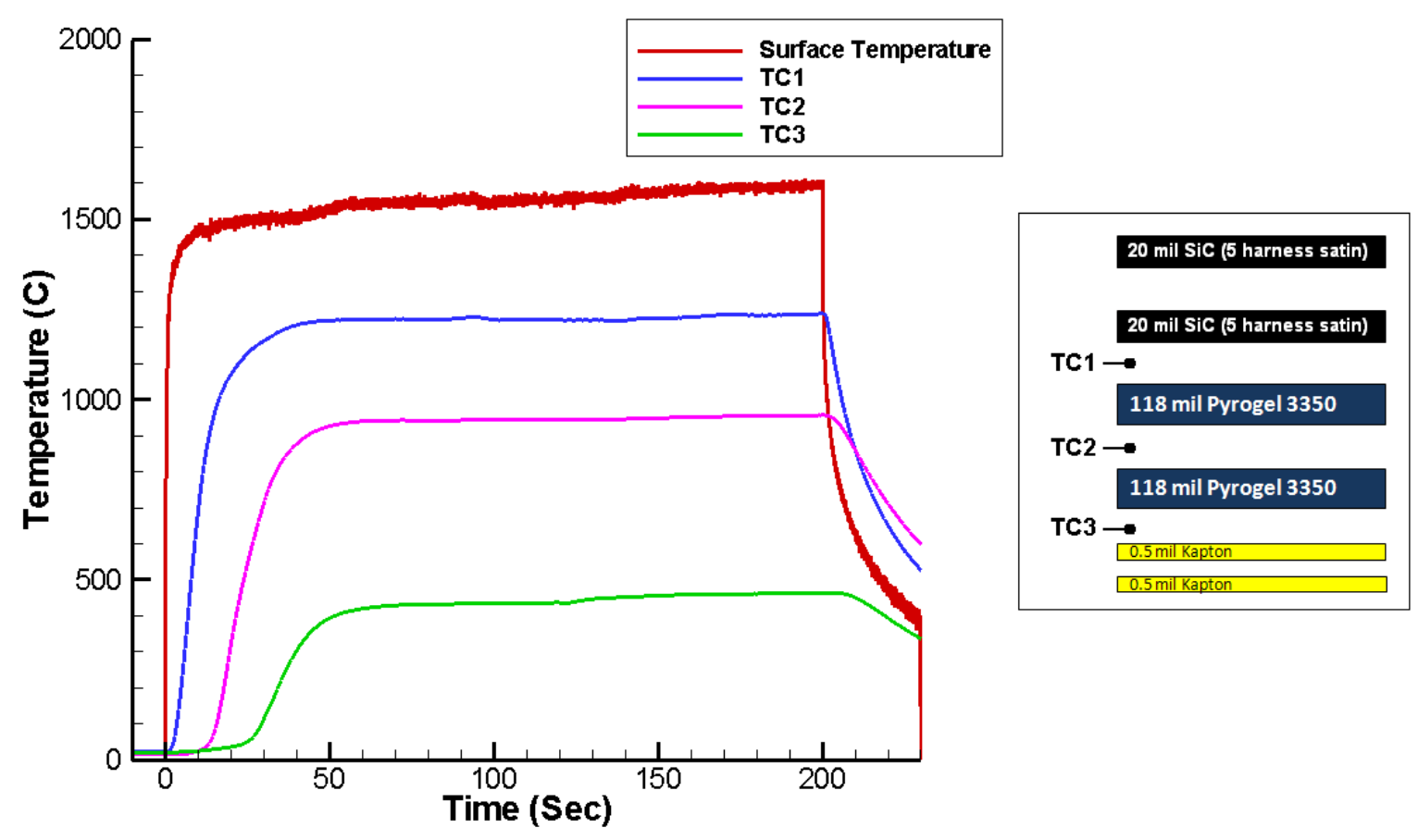

Figure 26. LHMEL thermocouple temperatures at various layers for the $\mathrm{SiC} 5 \mathrm{HS}$ layup tested at a heat flux of $50 \mathrm{~W} / \mathrm{cm}^{2}$ and pressure of 8 torr for 200 seconds. 


\section{Conclusions}

Ground testing that has been performed over the last three years of materials and concepts for the HIAD and ARMD Flexible TPS has been documented in this paper. Details on the overall goals of the testing, logic utilized in the TPS development effort, test facility capabilities, layups tested, material properties, and results of the IRVE-3 baseline TPS provided in this paper. Two new TPS material layups being advanced for future flight projects and an overview of the 1-D diffusion model has also been described in this paper.

Test techniques were developed at the 8'HTT, LHMEL, and PTF test facilities, respectively. Tests conducted at the 8'HTT most closely fit the trajectory calculated pressure, shear, and heating environments expected for the IRVE-3 flight project, as well as IRVE-4 and HEART flight concepts. Flexible TPS tests conducted at LHMEL were subjected to relevant pressure and heat flux conditions representative of a wide range of entry trajectory profiles, but did not have a shear component to stress the outer fabrics during heating. Tests conducted at PTF were able to produce much higher heat flux in a relevant shearing environment than was achievable at the 8'HTT, but did not meet surface pressures matching the calculated flight trajectories for IRVE-3 flight project nor IRVE-4 or HEART concept missions calculated flight trajectories.

The results from the tests conducted at 8'HTT, PTF, and LHMEL have verified that the IRVE-3 baseline TPS, made of two layers of Nextel BF-20, two layers of Pyrogel 3350, and two layers of Kapton was able to survive the $20 \mathrm{~W} / \mathrm{cm}^{2}$ heat flux calculated for the IRVE-3 flight test. Testing of the baseline TPS was conducted at longer durations, which is an over-test of the layup heat load relative to the calculated IRVE-3 flight trajectory.

Initial tests conducted at LHMEL, evaluating $\mathrm{SiC}$ outer fabrics, and PI-POSS polyimide transpiring insulators, indicate that the materials survive and will meet flight requirements. The $\mathrm{SiC}$ layup tests verified that two layers of $\mathrm{SiC}$ fabric, two layers of Pyrogel 3350, and two layers of Kapton were able to survive a $100 \mathrm{~W} / \mathrm{cm}^{2}$ incident radiant heat flux at relevant pressures for a reentry scenario. The advanced insulator layups, utilizing PI-POSS in place of Pyrogel 3350 insulator materials, showed great promise and will continue to be developed for future test and application.

Future efforts will be focused on three strategic areas. The first strategic area is development of a robust physics based model to generate accurate thermal analyses of material layups in relevant test environments. The physics based modeling effort will improve on the existing 1-D diffusion model by accurately capturing physics effects and the active state components of the insulators. The second strategic area is development of a materials characterization database. Accurate material properties at relevant temperatures are crucial to understanding and modeling thermal performance of flexible TPS layups. The third strategic area is ground testing of candidate material layups in relevant environments that capture potential flight opportunities. No single test facility will provide relevant heating, pressure, and shearing to accurately simulate reentry trajectories, therefore, understanding facility capabilities, and enveloping testing of flexible TPS to better understand failure mechanisms is important.

\footnotetext{
${ }^{1}$ Harvin, S.F., Cabell, K.F., Mekkes, G.L., and Gallimore, S.D., "Test Capability Enhancements to the NASA Langley 8-Foot High Temperature Tunnel”, JANNAF, 2006.

${ }^{2}$ Lander, M.L., Wolf, M.J., Daniels, C.R., Hull, R.J., "Laser-Hardened Materials Evaluation Laboratory (LHMEL) testing facility", SPIE Vol. 1624 Laser-Induced Damage in Optical Materials, Wright-Patterson AFB, OH, 1991

${ }^{3}$ Terrazas-Salinas, I., "Test Planning Guide for NASA Ames Research Center Arc Jet Complex and Range Complex", A029-9701-XM3 Rev. C, April 2009.

${ }^{4}$ Player, Charles, "PAIDAE Thermal Protection System Testing Final Report - FY2008", NASA Langley Research Center, PAI-DAE-3.3-012, 2008.

${ }^{5}$ Del Corso, J.A., Bruce, W.E., Liles, K.A., Hughes, S.J., "Thermal Analysis and Testing of Candidate Materials for PAIDAE Inflatable Aeroshell", $20^{\text {th }}$ AIAA ADS Conference, May 2009.

${ }^{6}$ Robert A. Dillman, Stephen J. Hughes, Richard J. Bodkin, David M. Bose, Joseph Del Corso, and F. McNeil Cheatwood: "Flight Performance of the Inflatable Reentry Vehicle Experiment II", 7th International Planetary Probe Workshop, Barcelona, Spain, June 14-18, 2010.

${ }^{7}$ NASA/SP-2010-577, "Evaluation of the NASA Arc Jet Capabilities to Support Mission Requirements", Office of the Chief Engineer, May 2010.

${ }^{8}$ Harvin, S.F., Cabell, K.F., Mekkes, G.L., and Gallimore, S.D., "Test Capability Enhancements to the NASA Langley 8-Foot High Temperature Tunnel”, JANNAF, 2006.

${ }^{9}$ Hughes, S.J., Ware, J.S., Del Corso, J.A., Lugo, R.A., "Deployable Aeroshell Flexible Thermal Protection System Testing", $20^{\text {th }}$ AIAA, ADS Conference, May 2009.
} 
${ }^{10}$ Daryabeigi, K., "Analysis and Testing of High Temperature Fibrous Insulation for Reusable Launch Vehicles", $37^{\text {th }}$ AIAA Aerospace Sciences Meeting and Exhibit, January 1999.

${ }^{11}$ Dynys, Fredrick, "Flexible TPS: Strength Degradation of Ceramic Tows/Fabrics upon Bending", Flexible TPS2011-001, Jan 2011.

${ }^{12}$ Guo, Haiquan, Meador, Mary Ann B., et al., "Polyimide Aerogels Cross-Linked through Amine Functionalized Polyoligomeric Silsesquioxane", Applied Materials and Interfaces, ACS Publications, January 17, 2011

${ }^{13}$ Bruce III, Walter E., "Aeroassist Inflatable Re-entry System (AIRS) Thermal Protection System (TPS) Thermal Analysis", STSB-2006-002, February 2006.

${ }^{14}$ Ferlemann, P.G. "Analysis of the Material Test Sled During Injection into the 8'HTT Test Flow", Technical Note 05-523, NASA Langley Research Center, October 29, 2008. 